\title{
Landslide susceptibility assessment in the Upper Orcia Valley (Southern Tuscany, Italy) through conditional analysis: a contribution to the unbiased selection of causal factors
}

\author{
F. Vergari, M. Della Seta, M. Del Monte, P. Fredi, and E. Lupia Palmieri \\ Dipartimento di Scienze della Terra, Università degli Studi di Roma "La Sapienza" P.le Aldo Moro, 5 - 00185 Rome, Italy \\ Received: 19 July 2010 - Revised: 7 March 2011 - Accepted: 29 March 2011 - Published: 19 May 2011
}

\begin{abstract}
In this work the conditional multivariate analysis was applied to evaluate landslide susceptibility in the Upper Orcia River Basin (Tuscany, Italy), where widespread denudation processes and agricultural practices have a mutual impact. We introduced an unbiased procedure for causal factor selection based on some intuitive statistical indices. This procedure is aimed at detecting among different potential factors the most discriminant ones in a given study area. Moreover, this step avoids generating too small and statistically insignificant spatial units by intersecting the factor maps. Finally, a validation procedure was applied based on the partition of the landslide inventory from multi-temporal aerial photo interpretation.

Although encompassing some sources of uncertainties, the applied susceptibility assessment method provided a satisfactory and unbiased prediction for the Upper Orcia Valley. The results confirmed the efficiency of the selection procedure, as an unbiased step of the landslide susceptibility evaluation. Furthermore, we achieved the purpose of presenting a conceptually simple but, at the same time, effective statistical procedure for susceptibility analysis to be used as well by decision makers in land management.
\end{abstract}

\section{Introduction}

Landslide hazard prediction can be difficult because it is often impossible to evaluate the spatial and temporal distribution of past events for large areas, due to gaps in the historical record and limited geographic information. Thus, several methods developed and implemented in this field of research

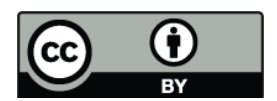

Correspondence to: F. Vergari (francesca.vergari@uniroma1.it) have focused on evaluating landslide susceptibility (see the reviews by: Brabb, 1984; Crozier, 1984; Carrara et al., 1995; Soeters and van Westen, 1996; Guzzetti et al., 1999). Landslide susceptibility methods are generally based on the statement that landslides are more likely to occur in the presence of the same conditions that led to past and present instability (Varnes, 1984; Carrara et al., 1991, 1995; Marini, 1995). For this reason, most of the landslide susceptibility evaluation methods are generally focused on the study of the factors influencing slope instability (causal factors).

Landslide susceptibility methods can be divided into three classes (Carrara et al., 1992): heuristic, deterministic, and statistical methods. In heuristic (or index) methods, the causal factors are weighted subjectively (Hollingsworth and Kovacs, 1981; Bosi et al., 1985; Neeley and Rice, 1990; Montgomery et al., 1991; van Westen et al., 1999). Deterministic models are based on the physical laws driving landslides (Okimura and Kawatani, 1987; Hammond et al., 1992; Montgomery and Dietrich, 1994; Terlien et al., 1995; Pack et al., 1999; Iverson, 2000) and are generally more suitable for small areas or for slope-specific stability studies. The statistical approach, instead, is founded on the multivariate relationships between causal factors and past and present landslide occurrence. The multivariate relationships are often identified through conditional analysis (BonhamCarter et al., 1989; Carrara et al., 1995), discriminant analysis (Agterberg, 1974; Carrara, 1983; Carrara et al., 1995, 2003; Baeza and Corominas, 2001), linear or logistic regression (Atkinson and Massari, 1998; Guzzetti et al., 1999, and references therein; Gorsevski et al., 2000; Dai and Lee, 2003; Ohlmacher and Davis, 2003; Ayalew and Yamagishi, 2005), and artificial neural networks (Aleotti et al., 1996; Lee et al., 2001; Wang and Sassa, 2006; Falaschi et al., 2009; Pradhan and Lee, 2010).

Published by Copernicus Publications on behalf of the European Geosciences Union. 
Statistical models have been developed to overcome the uncertainty due to subjective evaluation and are generally suitable for susceptibility assessment at catchment scale (as the present study case). In the statistical approach, particularly when applying conditional analysis, the causal factors are generally selected by the operator (Zêzere et al., 2005; Clerici et al., 2006; Conoscenti et al., 2008).

This work is aimed at assessing landslide susceptibility for the Upper Orcia River Basin, through the integration of the conditional analysis with an unbiased bivariate statistical procedure for selecting causal factors. Since the final purpose of the susceptibility analysis is to guide decision makers in land management, we propose a conceptually simple statistical methodology.

\section{Susceptibility assessment method}

\subsection{Methodological background}

The applied landslide susceptibility assessment procedure (Fig. 1) is part of a well-established group of statistical models. It is based on a method originally proposed in previous studies (Marini, 1995; Del Monte et al., 2002; Della Seta et al., 2005) and consisting of a multivariate analysis, where the conditional independence among causal factors had been assumed. In this study, the conditional dependence among factors is assumed and the susceptibility analysis is preceded by a new statistical procedure to select the most important causal factors for each type of landslide.

Separate analyses were performed for different landslide types as also suggested by Soeters and van Westen (1996), Guzzetti et al. (1999), Remondo et al. (2003). In fact, the most influential factors and their weights may vary considerably for different landslide types as well as, for the same type, in different areas. For the assessment of landslide susceptibility of the Upper Orcia Valley, we considered the most frequent landslide types in the area: mud flows, earth slumps, complex landslides, and portions of hillslopes affected by solifluction and very small mud flows, as described in detail in the following paragraphs.

The proposed procedure for factor selection is a bivariate statistical analysis aimed at understanding the distribution of the occurred landslides within the different classes of possible controlling factors. The selection of the causal factor, in fact, is based on the concept that the more the past events are concentrated in few classes of a factor, the more this factor will be important in discriminating the areas more or less prone to the future occurrence of that landslide type.

In this method, the study area was subdivided into subareas characterized by a unique combination of classes of pre-selected factors (Marini, 1995; Del Monte et al., 2002). These map units conceptually correspond to the Unique Condition Units (UCU, Carrara et al., 1995; Chung et al., 1995), but formally differ from them because in this study they come

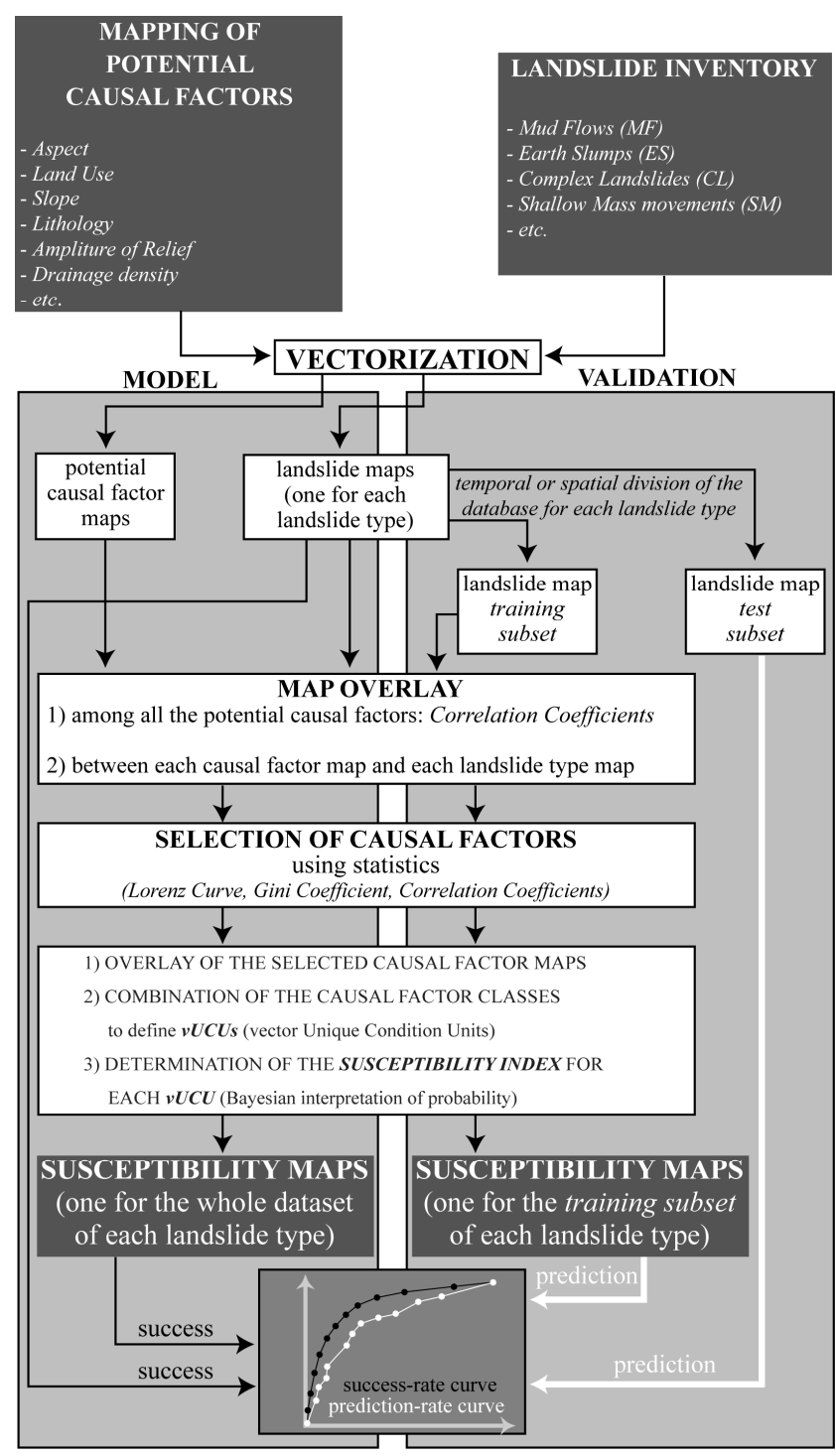

Fig. 1. Landslide susceptibility assessment procedure.

from vector datasets so that we called them vUCUs (vector Unique Condition Units). Moreover, the vUCUs are different for each landslide type susceptibility analysis, as a consequence of the application of the factor selection procedure. Vector datasets were used in order to obtain vector susceptibility outputs, which are expected to be less fragmented than the raster ones, and consequently more easy to be interpreted by users.

The conditional analysis is a multivariate statistical approach based on Bayesian theory, which considers the causal factors as conditionally dependent causes for landslide events (Bonham-Carter et al., 1989; Carrara et al., 1995). This statistical procedure is generally applied to calculate the susceptibility index for each map unit, where the simple attribution of an a priori landslide probability determination is 
conditioned, and thus updated, considering information on the combination of selected factors that caused past events.

A well-structured susceptibility evaluation procedure should consider the terrain conditions preceding the landslide events, since the failure occurrence could cause strong topographic modifications of these areas (Chung and Fabbri, 1999, 2008; Fernandez et al., 2003; Ayalew and Yamagishi, 2005; Nefeslioglu et al., 2008; Clerici et al., 2010). To test the best feature to be used for each landslide type, our procedure provides for the application of the susceptibility analysis using, for landslide inventory, the depletion zones and the outer buffer areas from the depletion zones, the latter to be dimensioned as a function of the input data resolution. In fact, the outer buffer area from depletion zones preserves pre-landslide conditions (Süzen and Doyuran, 2004), and it can also be affected by retrogressive activity of the landside process (Cruden and Varnes, 1996): it is, thus, very useful when input data about the terrain conditions preceding the instability events are not available.

We performed a validation, considering the importance of verifying the reliability of the spatial prediction model (Guzzetti et al., 2006). Several validation procedures have been proposed by different authors, with the aim of immediately testing the model, overcoming the difficulty of waiting for future landslides and comparing their distribution with the assessed classes of susceptibility. In this study, the validation procedure proposed by Chung and Fabbri (2003) was applied, in which a temporal subdivision of landslides is recommended: a training subset of data was exploited to produce a new prediction map (training susceptibility map), while the other subset (test subset) simulated the unknown target pattern, as better explained in the following paragraphs.

\subsection{Factor selection procedure}

The implementation of landslide susceptibility prediction models involves a series of tricky problems to be solved when identifying and mapping a suitable set of potential causal factors.

a. Identification and mapping of a suitable set of instability factors, bearing a causal relationship with slope failures needs an a priori knowledge of the main causes of landsliding (Guzzetti et al., 1999).

b. Once some potential causal factors have been correctly identified, a further constraint for a successful landslide susceptibility evaluation lies in their suitability for the study case: in fact, each causal factor can be more or less discriminant in explaining the distribution of the same landslide type in different study areas.

c. The identified controlling factors must then be classified in a suitable number of classes to best represent the variability of the factor values. In fact, too many classes lead to excessively small and diverse vUCUs and, thus, to low statistical significance of the landslide distribution in each vUCU, while too few classes can hide the effective variability of data. To perform an unbiased classification, the correct method should be chosen depending on the data frequency distribution (Jenks and Caspall, 1971).

d. Once the factor values have been correctly classified, it is necessary to select the correct number of factors, because, again, the greater the diversity of vUCUs, the lower the extent of the spatial units and, in turn, the lower the significance of the statistical analyses (Clerici et al., 2006, 2010). However, filtering techniques to cancel out or merge small and insignificant areas can introduce bias or errors in the procedure (Guzzetti et al., 1999). When using UCUs, the maximum number of causal factors to use in the landslide susceptibility assessment should depend on the extent and on the physiographic variability of the study area, as well as on the input data resolution.

Applications of simple statistical methods, such as conditional analysis, are rarely preceded by an unbiased causal factor selection procedure (He and Beighley, 2008). Some factor selection procedures, such as those proposed by Chung et al. (2002), Remondo et al. (2003) Clerici et al. (2010), provide for selecting the most significant factors after having computed all the possible susceptility maps from all the possible combinations of the potential causal factors and having tested the results by means of a validation method.

To select the most influencing factors likely responsible for future events in a given study area, we propose to use some statistical parameters before the application of the conditional analysis (Fig. 2), as a conceptually simple and effective method. This method is aimed at solving the above points (b), (c), and (d), considering that point (a) is common to all the approaches aimed at evaluating geomorphological susceptibility and is strongly depending on the operator knowledge of gravitational processes.

In particular, our factor selection consists of measures of inequality distributions (Gini, 1914), computation of Lorenz curves (Lorenz, 1905), and use of some indices of correlation between variables. Gini's index of inequality and Lorenz curves were conceived in the field of economics to measure social inequality and to represent income distribution over a population. In this study, we applied them to understand the distribution of occurred landslides within the different classes of influencing factors. The Lorenz curves were constructed after the intersection of each causal factor map with each landslide type map. Each point on the Lorenz curve (Fig. 2a) represents the cumulative area affected by a given landslide type versus the cumulative portion of the study area characterized by a certain class of a given potential causal factor. The line of perfect inequality (dotted line in Fig. 2a) represents the situation in which all the landslides of each 


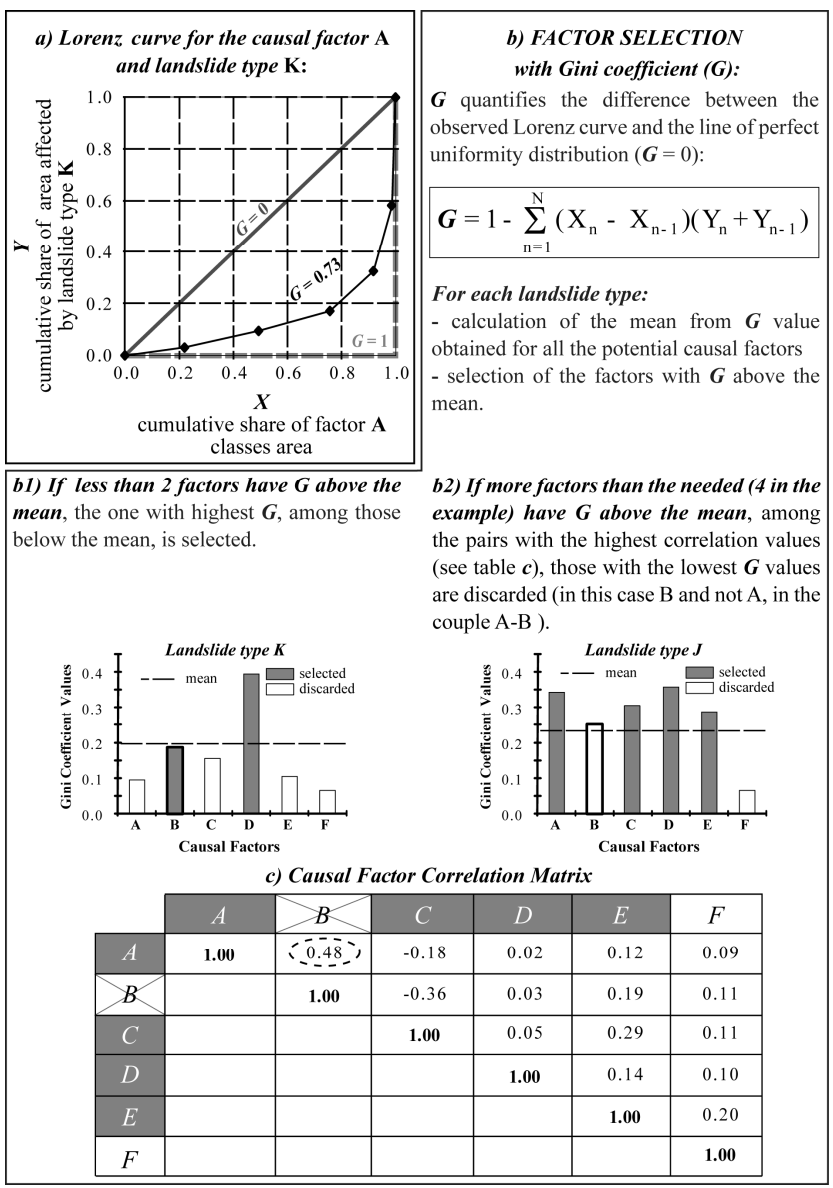

Fig. 2. Factor selection procedure: (a) example of Lorenz curve representing the distribution of landslide within the different classes of a potential causal factor $K$; the 1:1 solid line represents the homogeneous distribution of landslides with respect to factor classes, while the dotted line represents the perfect inequality distribution. (b) Factor selection based on Gini coefficient value $(G)$ with respect to the mean of the $G$-values of all the considered factors. (b1) Factor selection if only one factor has $G$-value above the mean. (b2) Factor selection if more factors than the needed number have $G$ value above the mean. The degree of correlation between these factors (c) has to be considered in order to discard, from the statistically correlated ones, those with lowest $G$-values.

type are clustered in a single factor class, whereas their homogeneous distribution in all the factor classes is represented by the line of perfect equality (the 1:1 solid line in Fig. 2a).

The Gini coefficient $(G)$ is graphically represented by the area between the line of perfect equality and the computed Lorenz curve, and it is expressed as the portion of the area between the line of perfect equality and the line of perfect inequality (Gini, 1914). This area can be approximated with trapezoids, and can be calculated using the following formula:

$G=1-\sum_{n=1}^{N}\left(X_{n}-X_{n-1}\right)\left(Y_{n}+Y_{n-1}\right)$ where: $n=$ factor class, $N=$ total number of factor classes, $X_{n}=$ cumulative portion of the study area characterized by the factor class $n$, with $X_{0}=0, X_{N}=1, Y_{n}=$ cumulative portion of landslide area falling in the factor class $n$, with $Y_{0}=0$, $Y_{N}=1$.

For each landslide type analysis, a factor was selected if the corresponding $G$-value was higher than the average of the coefficient values of all of the considered factors, as shown in Fig. 2b. The mean value is a simple measurement of the central tendency of the data and accounts for the specific range of $G$-values for each landslide type. In this way, independently of the absolute $G$-values, factors with $G$ higher than the mean value will be more discriminant than the others for the same landslide type occurrence in the study area. If only one factor has a $G$-value higher than the mean, then the factor with the second highest $G$-value must be selected as well (case b1 in Fig. 2). If more factors than the needed number have a $G$-value above the mean, we propose a method of exclusion based on the correlation between these factors, in order to avoid that the vUCUs provide redundant information about the landslide distribution (Clerici et al., 2010). Thus we computed a unique correlation matrix for all the possible pairs of potential factors using Pearson correlation when comparing two numerical variables (such as slope and drainage density), the Cramer Index when comparing two nominal variables (such as lithology and land use), and the $\eta^{2}$ index when comparing a numerical variable to a nominal variable (such as lithology and amplitude of relief) (Pearson, 1896; Cramer, 1999). So, when too many causal factors have $G$-values above the mean, from the pairs with the relatively highest correlation value, the factor with lowest $G$ value must be discarded (case b2 in Fig. 2).

The susceptibility evaluation for each landslide type was preceded by a careful evaluation of the best factor classification method.

\subsection{Susceptibility index determination}

Once the causal factors were finally selected for each landslide type, the conditional analysis allowed obtaining a number of vUCUs from all of the possible selected factor combinations in the study area. The susceptibility index for each vUCU (used to draw up the susceptibility maps for each considered landslide type) was successively calculated using the Bayesian interpretation of probability. The importance of applying conditional probability models has been strongly emphasized in the earth sciences literature, especially for predicting hazardous events or mapping mineral potential (Bonham-Carter et al., 1989), and was then applied by several authors for landslide susceptibility evaluation (Chung and Fabbri, 1999; Irigaray et al., 1999; Clerici et al., 2006, 2010; Zêzere et al., 2005; Conoscenti et al., 2008). The Bayes rule allows the probability of future landslide events to be predicted once the area of each vUCU affected by past landslides is known. The Bayes rule specifies 
a prior probability, which is then updated in light of new relevant data (called "likelihood" in Bayesian theory). In the study case, this means that the simple attribution of an a priori determined probability has to be updated considering information on past events. Thus, the susceptibility index corresponds to the conditional (or posterior) probability $P(f \mid \mathrm{vUCU})$, which is the probability of the occurrence of a landslide type given a certain combination of selected causal factors (vUCU). If we consider as an example a vUCU defined by the spatial combination of the areas pertaining to two classes of two causal factors $k_{\mathrm{g}}$ and $j_{\mathrm{h}}$ (where $k$ and $j$ represent two causal factors, such as lithology and hillslope aspect, and $\mathrm{g}$ and $\mathrm{h}$ represent single classes of the factors), the susceptibility index is:

$P\left(f \mid k_{\mathrm{g}} \bigcap j_{\mathrm{h}}\right)=\frac{P\left(k_{\mathrm{g}} \bigcap j_{\mathrm{h}} \mid f\right)}{P\left(k_{\mathrm{g}} \bigcap j_{\mathrm{h}}\right)} \cdot P(f)$

where: $P(f)=$ prior probability of landslides $(f=$ ratio of the study area presently characterized by landslides);

$\frac{1}{P\left(k_{\mathrm{g}} \bigcap j_{\mathrm{h}}\right)} \quad=$ proportionality factor $=1 /$ ratio of the study area presently characterized by the concomitant presence of $k_{\mathrm{g}}$ and $j_{\mathrm{h}}$, in which the denominator indicates the prior probability of the simultaneous presence of the two classes of the factors $k$ and $j$ (for example clayey outcrops for lithology factor, and north-facing slopes for aspect factor); $\mathrm{P}\left(k_{\mathrm{g}} \bigcap j_{h} \mid f\right)=$ conditional probability (likelihood or updated value of probability) of the simultaneous presence of the two classes of the factors $k$ and $j$, given the landslides $f=$ area of intersection between $k_{\mathrm{g}}, j_{\mathrm{h}}$ and area affected by landslides $f$ / total area presently characterized by landslides; and $P\left(f \mid k_{\mathrm{g}} \bigcap j_{\mathrm{h}}\right)=$ posterior probability of landslides $f$, which is proportional to the prior probability updated with the likelihood.

The susceptibility index ( $S_{\text {index }}$ ) for each $i$-th vUCU and each landslide type can be computed more easily because it corresponds to the ratio between the landslide area affecting $\mathrm{vUCU}_{i}\left(A f_{\mathrm{vUCUi}}\right)$ and the area of $\mathrm{vUCU}_{i}\left(A_{\mathrm{vUCUi}}\right)$ :

$S_{\text {index }}=\frac{A f_{\mathrm{vUCUi}}}{A_{\mathrm{vUCUi}}}$

The $S_{\text {index }}$ values for each vUCU indicate the probability of the landslide type occurrence conditioned by the concomitant presence of the selected causal factor categories. $S_{\text {index }}$ of a vUCU may be expressed by a percentage, thus theoretically ranges between 0 and $100 \%$, where $100 \%$ is the maximum probability of a landslide event, given by the complete coverage of the vUCU by landslides.

\subsection{Validation procedure}

We applied the method by Chung and Fabbri (2003) in order to choose the most meaningful among the obtained susceptibility maps for each landslide type. This method provides for a chronological or spatial partition of the landslide database into a training subset and a test subset (Fig. 1), considering the second one as the unknown future target pattern of landslides. The same susceptibility procedure previously applied to the whole landslide inventory must be applied to the only landslide training subset, thus obtaining a training susceptibility map for each considered landslide type. Finally the distribution of the test landslide subset is compared with the training susceptibility maps. For each landslide type, by intersecting each training susceptibility map (obtained using the only training subset) with the landslides of the test subset, it is possible to construct the prediction-rate curve, while the success-rate curve is elaborated by comparing each susceptibility map (obtained by considering the whole set of each landslide type) with the distribution of all the landslides that have been used to obtain this map (Fig. 1). Since we propose to use vector layers, the curves are constructed by plotting the cumulative area of vUCUs ordered by decreasing $S_{\text {index }}$ values (x-axis) versus the cumulative area affected by landslides within each vUCU (y-axis).

As it is generally assumed that future landslides will occur in the same conditions that provoked the already occurred ones in the same area, the success-rate curve measures the model fitness, assuming that the model is correct. On the other hand, the prediction-rate curve provides a measure of the predictive capability of the model. Ideally, the tangent of a prediction-rate curve should be monotonically decreasing, to indicate that the most hazardous classes predict most of the "future" landslides, and the trend regularly decreases with the gradual reduction of the susceptibility value. However, as described by Chung and Fabbri (2003), empirical predictionrate curves usually do not satisfy this condition. A 1:1 trend of the prediction-rate curve indicates that the prediction map is randomly generated. Thus, the further the prediction-rate curve is from a straight line, the more the susceptibility estimation is significant. Moreover, the steeper the curve is in its first part, the greater the predictive power of the prediction map (Remondo et al., 2003).

\section{Landslide susceptibility evaluation for the Upper Orcia Valley}

The landslide susceptibility method was applied in the Upper Orcia Valley, which is the easternmost portion of the Ombrone River basin (Fig. 3). The area is located in the Tuscan Pre-Apennines, close to Siena, north of Radicofani, and it covers about $120 \mathrm{~km}^{2}$, with an altitude ranging from about 350 to $1148 \mathrm{~m}$ a.s.l. (Mt. Cetona). The drainage pattern and catchment shape are structurally controlled by the regional morphostructure of the Radicofani Graben (Baldi et al., 1994; Carmignani et al., 1994), whose major axis is oriented NW-SE. The location of the Orcia River basin southern divide, which corresponds to the boundary between the Tevere River and Ombrone River basins, is controlled by the 


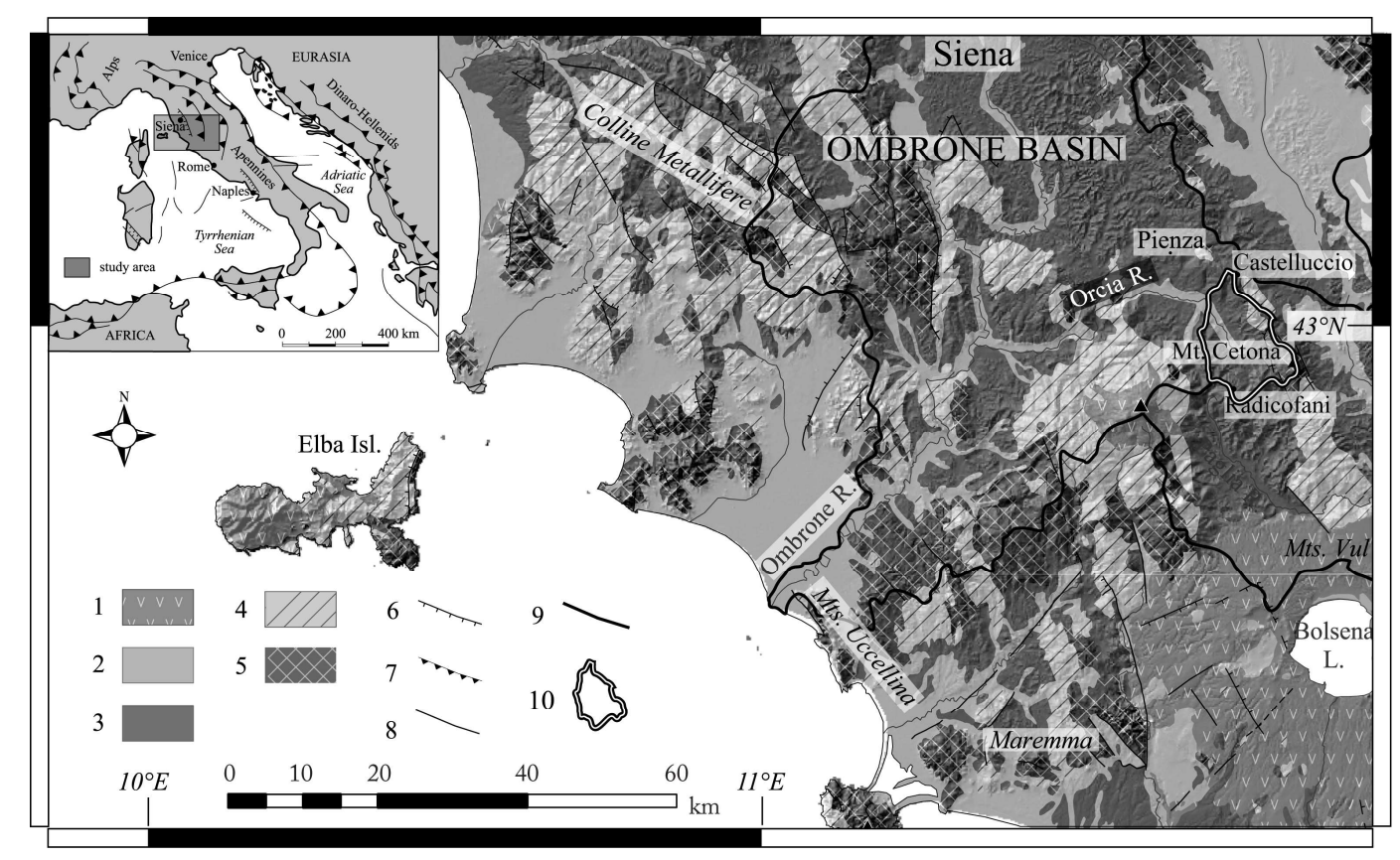

Fig. 3. Location of the study area and geological sketch of the Tyrrhenian side of central Italy: (1) Quaternary volcanic rocks; (2) Quaternary undifferentiated continental deposits; (3) Plio-Pleistocene terrigenous marine deposits and Messinian evaporites; (4) sedimentary and metamorphic units of Ligurian and sub-Ligurian nappes (Trias to Lower Cretaceous); (5) sedimentary and metamorphic units of Tuscan nappe (Paleozoic to Miocene); (6) normal fault; (7) overthrust and reverse fault; (8) undetermined fault; (9) watershed; (10) study area.

Monte Cetona horst and the Monte Amiata and Radicofani Quaternary volcanoes.

\subsection{Geological, climatic and geomorphological features}

The geological evolution of the study area is responsible for widespread outcrops of lithological units prone to denudation (Fig. 3). The emplacement of the Apennine orogenic wedge (Oligocene to Tortonian) led to the formation of major morphostructures oriented mainly NW-SE and made up of sedimentary sequences (Umbria-Marche sequence, Tuscan Nappe, Ligurian and Subligurian Nappe) overthrusted towards the NE (Buccolini et al., 2010). The later collapsing phase started in the Late Miocene, and the extensional tectonics, affecting the Tyrrhenian margin of the Italian peninsula, activated several NW-SE-striking normal faults that defined a system of horsts and grabens (Baldi et al., 1994; Carmignani et al., 1994) cut by SW-NE transfer faults. A marine transgression led to the deposition of a Plio-Pleistocene sequence of clay, sands, and conglomerates within the major depressions: Radicofani Graben, Val di Chiana Graben, and Tevere Graben. Inland, the extensional basins are filled with lacustrine to fluvio-lacustrine continental deposits. During the Quaternary, the Plio-Pleistocene marine deposits were uplifted to several hundreds of meters above the present sea level (Liotta, 1996). This strong uplift was related to pluton emplacement and widespread volcanic activity along the
Tyrrhenian side (Acocella and Rossetti, 2002), evidenced by the alignment of many volcanic complexes. Quaternary uplift has been particularly strong along the southern margin of the Radicofani Graben, where locally marine deposits crop out at $900 \mathrm{~m}$ a.s.l. (from the Mt. Amiata-Radicofani neck, on the western side, to Mt. Cetona on the eastern slope of the study area) and was responsible for the slight tilting of these deposits towards the NE in the Upper Orcia Valley.

Climate data from the 1951-1996 records at several significant stations within the eastern Ombrone River Basin indicate that the mean annual rainfall $(696 \mathrm{~mm})$ is below the national average $\left(970 \mathrm{~mm} \mathrm{a}^{-1}\right)$, although its values during the considered time span are discontinuous. Rainfall is heavier in the colder half of the year than in the summer, with a maximum in November and a minimum in July. The most consecutive rainy days are recorded in autumn. The mean annual temperature is around $14^{\circ} \mathrm{C}$, and the thermal regime indicates an annual range of about $18^{\circ} \mathrm{C}$, with a maximum in July.

The variety of outcropping lithologies and the tectonic control led to the development of structural landforms. The major landforms are represented by morphostructural ridges bounded by NW-SE-trending fault scarps, dipping towards the graben depressions. Minor morphotectonic elements (e.g., straight channels, saddles, straight ridges) are aligned along (and controlled by) the other structural patterns. However, the study area is characterized by hilly landscapes, 
with elevations rarely higher than $1000 \mathrm{~m}$ a.s.l., due to the widespread outcrops of soft sediments. Fluvial erosion, together with slope denudation, contributes significantly to the morphogenesis. A lot of slopes are rapidly evolving, and the rivers show high suspended sediment load. Water erosion is pervasive, due to extensive clayey outcrops as well as to the current climatic conditions and the rapid uplift, leading to typical sharp- and rounded-edged badlands, locally called calanchi and biancane, respectively (Della Seta et al., 2009, and references therein).

Landslides provide the major contribution to slope denudation, together with water erosion (Della Seta et al., 2009; Ciccacci et al., 2008), so that they supply a considerable amount of material to be transported by the major rivers. Apart from some rock falls, earth slumps and earth slides occur on steep slopes. However, the influence of gravity is also evident on gentler slopes, where mud flows, soil creep and solifluction are widespread. Due to these prevailing morphogenetic processes, gently undulating slopes characterize the landscape.

Human activity has significantly affected the landscape for a long time. Deforestation, grazing, and farming are among the most important triggers for accelerated water erosion, tillage erosion, and gravitational movements on slopes. Moreover, the effects of farming may become stronger if there are land-use changes related to cropland abandonment.

\subsection{Landslide inventory map}

The landslide inventory map (Fig. 4) has been drawn up at the scale of 1:10000 through geomorphological field surveys and the interpretation of 1988-1989 aerial photographs (Volo Italia, performed by Compagnia Generale Ripreseaeree S.p.A. at a scale of about 1:70000), and 1993 aerial photographs of Regione Toscana (performed by C.G.R. S.p.A., scale 1:30000). This multi-temporal interpretation also allowed the temporal division of the landslide database into two subsets in order to perform the validation procedure.

The Upper Orcia River valley slopes are widely affected by landslides, solifluction, and creep. According to the landslide classification of Cruden and Varnes (1996), we considered the most frequent typologies of landslides, which are mud flows (MF), earth slumps (ES) and complex landslides (CL). Moreover, we used the term shallow mass movements (SM) to represent a fourth category that consists of portions of hillslopes affected by solifluction and very small and frequent mud flows, and whose extent is not mappable at the study scale (1:10000). These landforms were mapped after field survey, thus they lack the temporal information. We discarded rock fall landslides and earth slides because they are too few and small to be significant for the statistical analysis of susceptibility. It is noteworthy that all the detected and mapped landslides are recent and active and thus comparable to the time scales of all of the considered factors.
All landslide types were mapped and digitized in a GIS environment as vector datasets. For the same type of landslide, we ran the susceptibility evaluation model twice, using first the depletion zones and then an outer buffer from depletion zones. For the study case, we discarded the possibility of using a buffer size proportional to the landslide extent and considered as significant a fixed buffer of $50 \mathrm{~m}$. In fact, proportional buffers would have caused the smallest ones to be not significant with respect to the resolution of the input data and the largest ones to include too much spatial variability of the causal factor values. We removed the portion of the buffer areas passing over the divide line and dissolved the buffer polygons when intersecting each other.

We used both depletion and buffer areas for all the landslide types, except for SM. In fact, for SM we considered the whole instable areas because detachment and accumulation zones are not detectable at the spatial and temporal scales of the study. Figure 4 shows the $50 \mathrm{~m}$ outer buffer areas from the depletion zones, the accumulation zones and the detachment zones for the considered landslide types, as well as the extent of the datasets used for susceptibility and validation analyses.

MF are very frequent in the study area due to the widespread outcrops of clays (Fig. 5a). As observed during the monitored time span, these flows can be reactivated several times in one year, especially during the winter halfyear, although intensive agricultural activity has recently and frequently leveled these landforms (Della Seta et al., 2009; Ciccacci et al., 2008). Small but frequent MF have been observed on badlands slopes or where the bare clayey bedrock crops out.

ES are frequent in the eastern part of the study area and sometimes show considerable extent (Fig. 5b). Although anthropogenic actions have tried to mitigate the effects of landslides, these processes are so strong that, just 24 or $48 \mathrm{~h}$ after a rainstorm, significant modifications of the topographic surface appear on slopes. ES often evolve to earth flows towards the toe, giving rise to CL (Fig. 5c).

SM produce typical lobes and irregular surfaces on hillslopes (Fig. 5d), even if showing gentle slope, especially those affected by deforestation. The same hillslopes are affected by small and frequent mud flows, often leveled by farmers. These landslides are difficult to map because surface running waters rapidly reshape the surface. In these cases, we mapped the portions of slopes affected, on the whole, by SM.

We decided to apply the susceptibility evaluation procedure separately for each landslide type since in the area the occurrence of different landslide types can produce very different effects on hillslopes: MF (Fig. 4a) generally cause long and narrow surface landslide bodies, ES (Fig. 4b) are deeper, involving large volumes of material, and SM (Fig. 4d) are not single gravitational landforms but rather instability events affecting entire portions of hillslopes. As for $\mathrm{CL}$, they generally provoke an elongation of the deposits at 


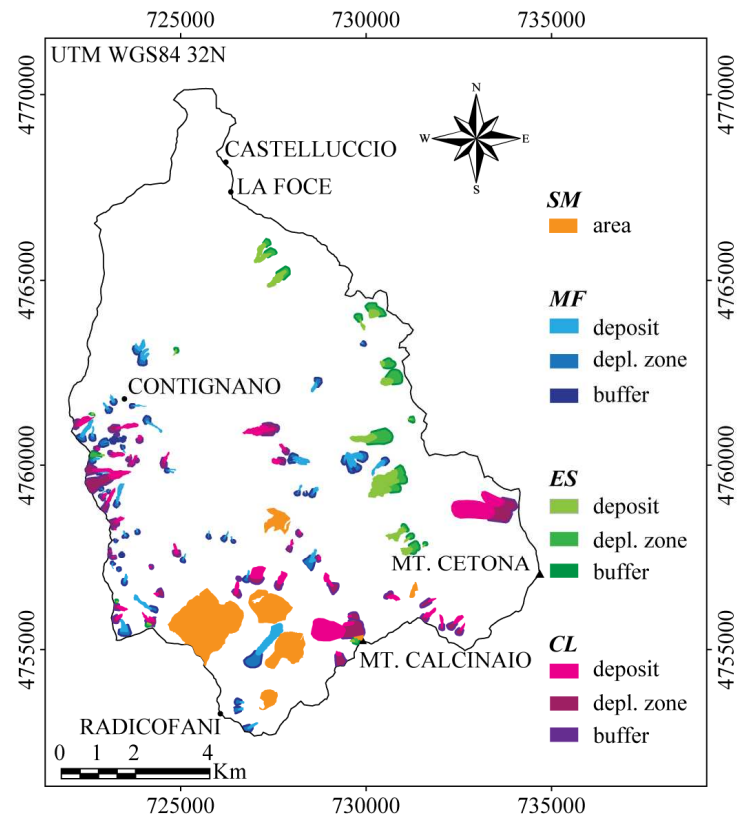

\begin{tabular}{|c|c|c|c|c|c|c|c|}
\hline $\begin{array}{l}\text { Landslide } \\
\text { type }\end{array}$ & $\begin{array}{c}\text { Slope } \\
\text { instability } \\
\text { landform }\end{array}$ & $\begin{array}{c}\text { Number } \\
\text { of events }\end{array}$ & $\begin{array}{l}\text { Total area } \\
\left(\mathrm{m}^{2}\right)\end{array}$ & $\begin{array}{c}\text { Training } \\
\text { subset area } \\
\left(\mathrm{m}^{2}\right) \\
\end{array}$ & $\begin{array}{c}\text { Test subset } \\
\text { area } \\
\left(\mathrm{m}^{2}\right)\end{array}$ & $\begin{array}{c}\text { Mean single } \\
\text { landslide area } \\
\left(\mathrm{m}^{2}\right)\end{array}$ & $\begin{array}{c}\text { Standard } \\
\text { deviation } \\
\left(\mathrm{m}^{2}\right)\end{array}$ \\
\hline \multirow{2}{*}{ MF } & $50 \mathrm{~m}$ buffer & \multirow{2}{*}{57} & 1137164.12 & 715153.35 & 422010.77 & 23931.19 & 12661.83 \\
\hline & depletion zone & & 537932.49 & 407500.22 & 130432.26 & 9437.41 & 14657.23 \\
\hline \multirow{2}{*}{ ES } & $50 \mathrm{~m}$ buffer & \multirow{2}{*}{22} & 633906.25 & 555189.03 & 78717.23 & 28810.36 & 24956.79 \\
\hline & depletion zone & & 641726.10 & 610102.10 & 31624.00 & 29169.37 & 32217.75 \\
\hline \multirow{2}{*}{ CL } & $50 \mathrm{~m}$ buffer & \multirow{2}{*}{50} & 1196634.99 & 593025.79 & 603609.20 & 22159.91 & 13699.06 \\
\hline & depletion zone & & 1136649.00 & 851086.06 & 285562.94 & 22732.98 & 35712.48 \\
\hline SM & $\begin{array}{c}\text { portion of } \\
\text { hillslope } \\
\text { affected by SM }\end{array}$ & 7 & 4314729.99 & \multicolumn{2}{|c|}{ / } & 616389.99 & 695859.19 \\
\hline
\end{tabular}

Fig. 4. Landslide inventory maps. For each landslide type, the deposit, the depletion zone, and the $50 \mathrm{~m}$ outer buffer area from the depletion zone are shown. Total area and mean extent of each landslide type are listed in the table.

their toe (Fig. 4c) and were, thus, considered separately from ES for the susceptibility analysis.

\subsection{Potential causal factors}

We chose six potential causal factors as suitable in accounting for the physiographic conditions of the study area, and mapped their spatial distributions, as shown in Fig. 6. The values of each variable have been classified, and, for each landslide type, the fraction of the total landslide area within each factor class was evidenced in histograms. For clarity of the outputs, we decided to work with vector data, so each raster layer, derived from a DTM with a resolution of $25 \mathrm{~m}$, was converted to a vector dataset. The DTM was constructed from digitized point elevation and contour lines of the 1994 topographic maps at scale 1:10000 of Regione Toscana and from it we derived the terrain analysis parameters slope, aspect and amplitude of relief.

\subsubsection{Slope $(S)$}

The slope map (Fig. 6a) was derived from the $25 \mathrm{~m}$ cell-sized DTM, using the analysis tools in ArcGIS 3-D-Analyst. The output raster was aggregated (nearest-neighbor re-sampling technique) to a $50 \mathrm{~m}$ cell-sized grid, to avoid the excessive fragmentation of the vUCUs. $S$-values were grouped into six classes using the Jenks (natural breaks) method, and the raster dataset was converted to a vector format. Classes from 1 to 4 are all widespread within the study area (16\% to $26 \%)$, whereas classes 5 and 6 cover, respectively, $6.8 \%$ and $1.5 \%$ of the area and are concentrated where the most coherent lithologies crop out.

The distribution of depletion zones in $S$-classes (Fig. 6a) seems to be gaussian, with some differences in the mode, depending on the landslide type: MF and SM have their mode in class 3, ES are more concentrated in class 4, and CL are very frequent in both classes 3 and 4 . The distribution of 

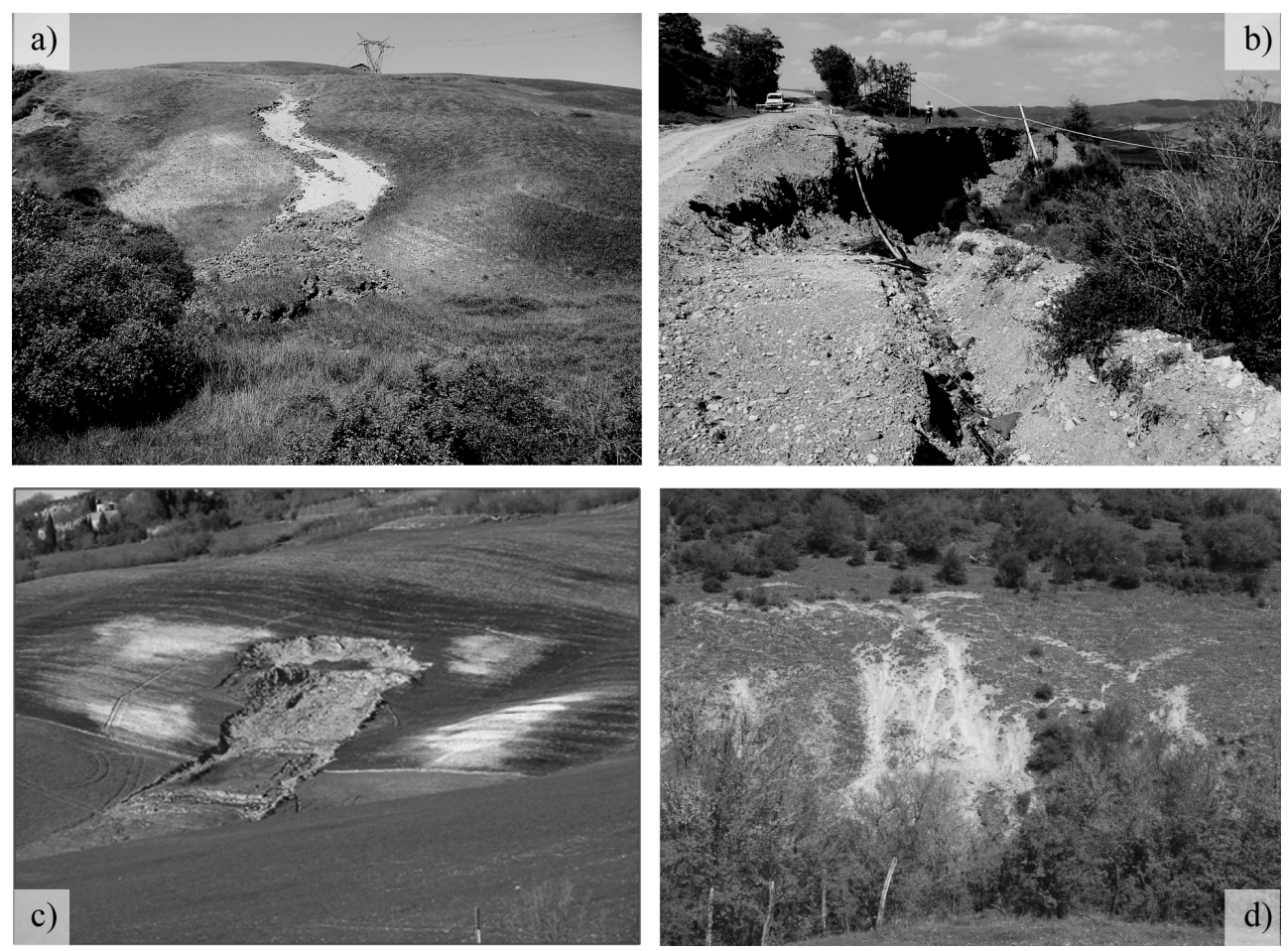

Fig. 5. Examples of the landslide types widespread in the study area: (a) mud flow; (b) earth slump; (c) complex landslide (earth slump evolving into a mud flow); (d) shallow mass movements.

the outer buffer areas from depletion zones shows a similar distribution, but with smaller frequency differences among the $S$-classes.

\subsubsection{Aspect $(A)$}

The aspect map (Fig. 6b) was derived using the terrain analysis tool in GIS environment. The $50 \mathrm{~m}$ cell-size raster output was classified into five groups of $A$ (flat, N, S, E, W). The horizontal areas do not have significant extent, while the other classes are all well distributed in the study area. ES show a progressive increase in frequency, going clockwise from the $\mathrm{N}$ class to the $\mathrm{W}$ class. The frequency of $\mathrm{CL}$ also shows a maximum on west-facing slopes, even if they also occurred on northeast-facing slopes. This can be understood considering the structural influence related to the right slope of the Upper Orcia Valley. MF are preferentially concentrated on the north- and east-facing slopes (generally corresponding to dip slopes) and show the lowest frequency on west- and south-facing slope, such as SM. These distributions can be explained considering that the development of MF needs wetter conditions, even if the relationship between landslides and $A$ is also conditioned by other factors.

\subsubsection{Amplitude of relief (AR)}

The amplitude of relief map (Fig. 6c) represents the maximum difference in height per unit area and was derived by raster calculations from the DEM in ArcGIS. We decided to visualize the results using contour lines and to derive from them a polygonal vector dataset, which was classified using the natural breaks method. This parameter provides a measure of fluvial erosive action. It was verified that, other conditions being equal, the spatial distribution of this parameter can provide information about vertical displacements (e.g. local fault activity or regional uplift) (Della Seta et al., 2004).

As shown in Fig. 6c, the highest AR-values are clustered along the basin's northeastern divide, where the western flank of the Castelluccio-Mt. Cetona horst is bounded by fault scarps.

Although the lowest classes of this factor are widespread in the area, ES are concentrated in class 4. On the other hand, AR-factor does not seem particularly significant in MF distribution, which is quite homogeneous in classes 2, 3, and 4. The distribution of CL indicates an intermediate behaviour, while SM are more frequent in classes 3 and 4 . Concerning the buffer area, ES, MF, and CL have a frequency distribution similar to that of the depletion zone, but for the AR-factor, the differences among the frequencies in the factor classes are less relevant. 

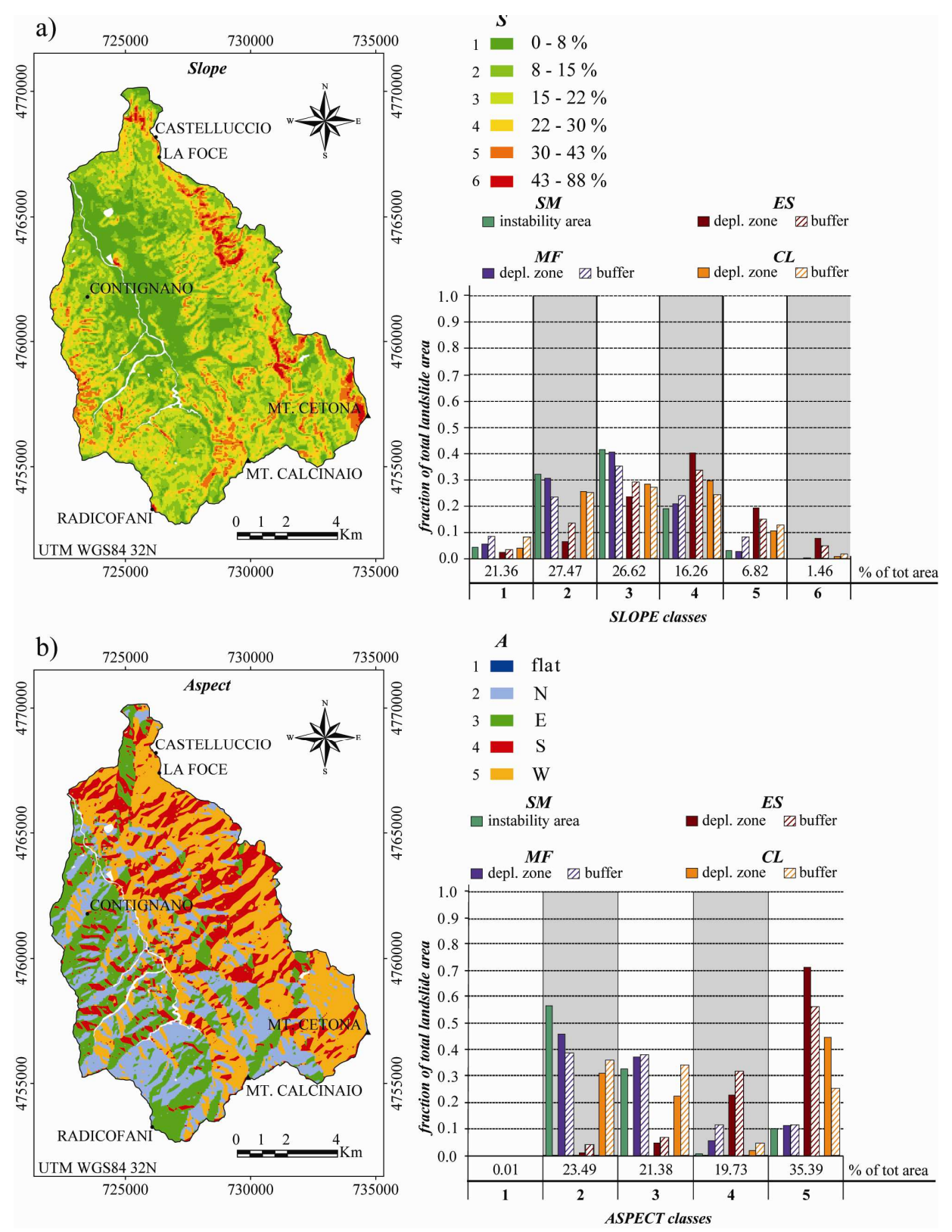

Fig. 6. (a, b) Thematic maps showing the spatial distribution of potential causal factors for landslides: (a) Slope $(S)$; (b) Aspect $(A)$; (c) Amplitude of Relief (AR); (d) Drainage density (D); (e) Land Use (LU); (f) Lithology $(L)$. The values of each variable were classified and, for each landslide type, the fraction of the total landslide area within each factor class is reported in the histograms.

\subsubsection{Drainage density $(D)$}

The drainage density map (Fig. 6d) was derived by calculating the cumulative length of stream segments of the drainage network digitized from 1:25000 topographic maps falling within unit areas of $1 \mathrm{~km}^{2}$. As for the AR map, we decided to visualize the map using contour lines and to derive from them a polygonal vector dataset classified into equal intervals of $D\left(2.5 \mathrm{~km} \mathrm{~km}^{-2}\right) . D$ is a parameter which indirectly accounts for the erodibility and permeability of outcropping rocks, the degree of tectonization, the vegetation cover, the slope gradient, and the mean annual raifall in the drainage basin. More than $50 \%$ of the study area is characterized by high or very high $D$-values (between 5 and $12.5 \mathrm{~km} \mathrm{~km}^{-2}$ ), due to the widespread outcrop of clays $(73 \%$ of the total area). Moreover, the heads of several catchments are affected by badlands, where runoff is absolutely dominant with respect to infiltration.

Most of the ES fall in class 2 of this factor, highlighting that they are preferentially concentrated where infiltration is 

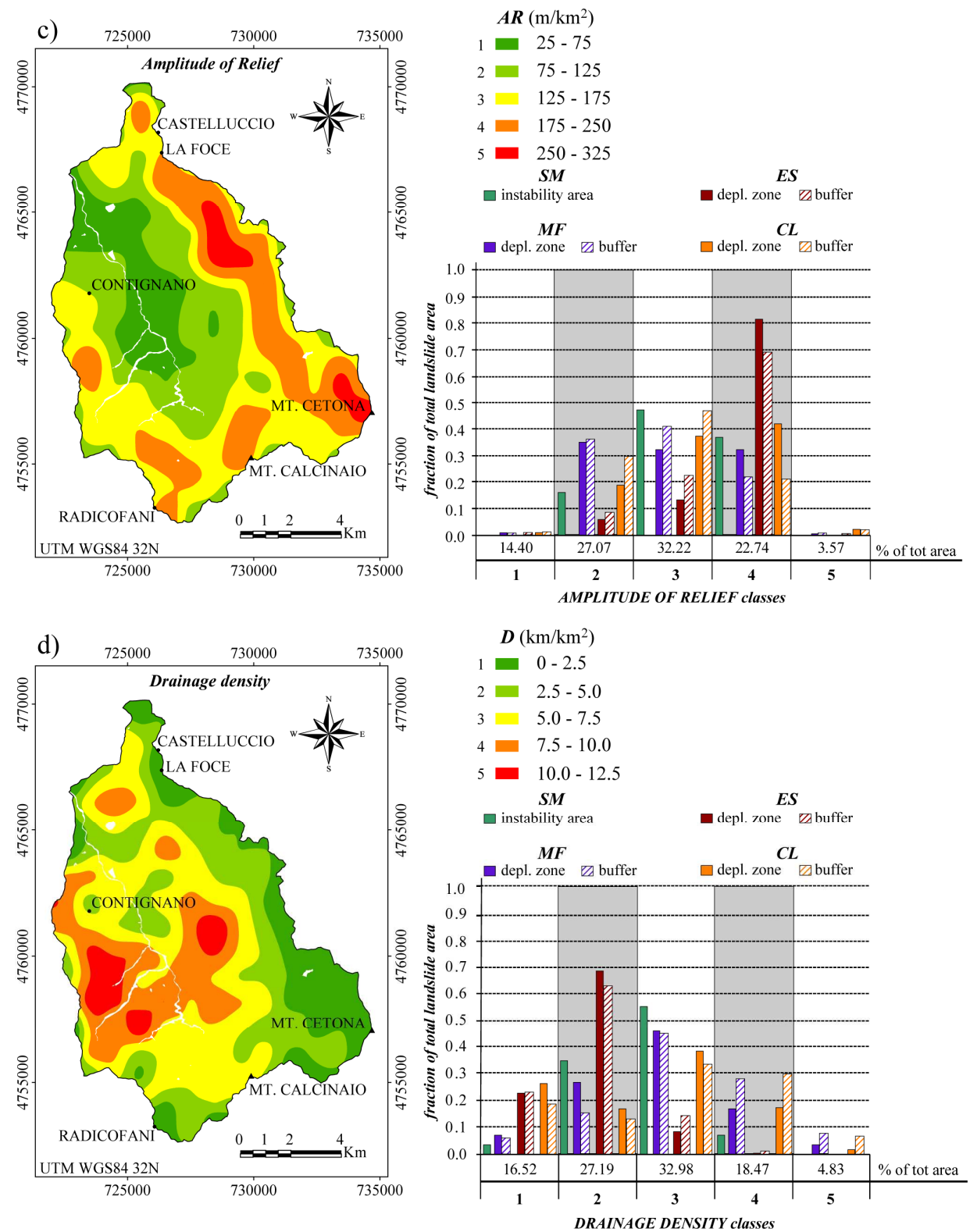

Fig. 6. (c, d) Thematic maps showing the spatial distribution of potential causal factors for landslides: (a) Slope $(S)$; (b) Aspect $(A)$; (c) Amplitude of Relief (AR); (d) Drainage density (D); (e) Land Use (LU); (f) Lithology $(L)$. The values of each variable were classified and, for each landslide type, the fraction of the total landslide area within each factor class is reported in the histograms.

considerable. On the other hand, MF and SM are favored by higher values of $D$ (maximum frequency in class 3 ), while CL do not seem to be much influenced by this factor. Considering the buffer area distribution with respect to $D$-values, the frequency of MF in the highest $D$-classes appears enhanced.

\subsubsection{Land use (LU)}

The land use map (Fig. 6e) was drawn up after the interpretation of 2004 digital orthophotos (Volo Siena 2004, at a scale of about 1:7500) and field surveys. We used and simplified the Corine Land Cover legend (1st, 2nd, and 3rd levels; EEA, 2007), as indicated in Table 1. For the susceptibility analysis, we excluded the areas occupied by lakes and stream beds permanently filled by waters, that are not as useful for the susceptibility evaluation. The density of landslides within each LU-class shows a maximum frequency in the three more frequent classes (arable lands, untilled lands, and hardwood natural forests). In particular, ES occur especially on forestcovered slopes, MF on arable lands, and SM and CL on natural grasslands. 

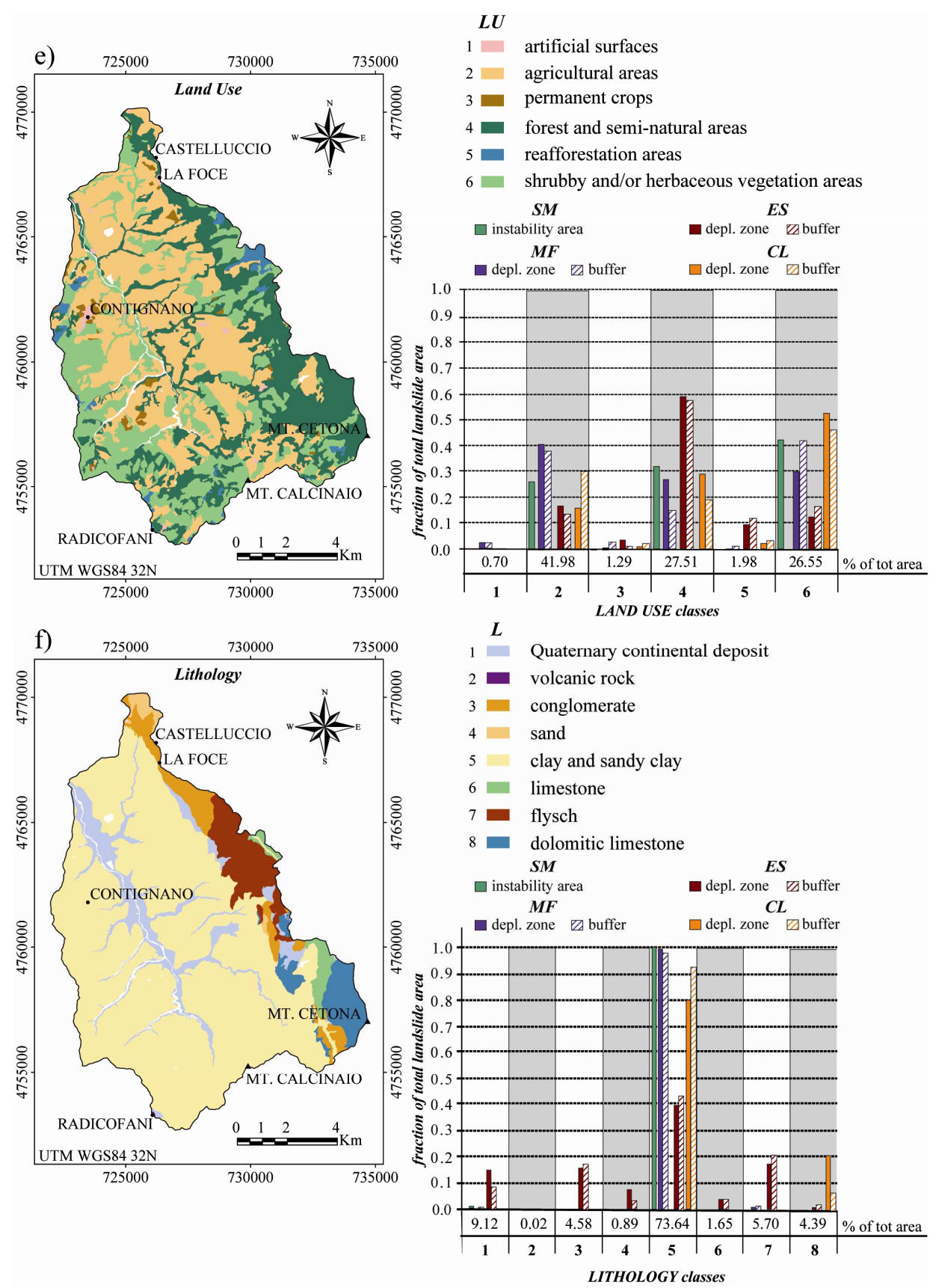

Fig. 6. (e, f) Thematic maps showing the spatial distribution of potential causal factors for landslides: (a) Slope $(S)$; (b) Aspect $(A)$; (c) Amplitude of Relief (AR); (d) Drainage density (D); (e) Land Use (LU); (f) Lithology $(L)$. The values of each variable were classified and, for each landslide type, the fraction of the total landslide area within each factor class is reported in the histograms.

\subsubsection{Lithology $(L)$}

The lithological map (Fig. 6f) was drawn up by grouping the outcropping rocks according to their response to denudation processes, as summarized in Table 2. The geological setting of the area is well known, and the rock units reported in the existing geological map have been grouped into eight lithological units.
Figure $6 \mathrm{f}$ also shows the frequency of each landslide type in each $L$-class. This distribution is obviously influenced by the extent of outcrops in the study area (clayey deposits cover about $73 \%$ of the Upper Orcia river basin, while volcanic rocks only crop out on the Radicofani neck, which is statistically meaningless for the study area). Nevertheless, we included this factor in the susceptility assessment procedure, since the selection method is conceived precisely in order to 
Table 1. Classification of Corine Land Cover units in land use classes.

\begin{tabular}{lll}
\hline Land use units & \multicolumn{2}{l}{ Corine land cover units } \\
\hline 1. Artificial surfaces & 1 & (artificial surfaces) \\
\hline 2. Agricultural areas & 2.1 & $\begin{array}{l}\text { (arable land) } \\
\text { (pastures) } \\
\text { (heterogeneous agricultural areas) }\end{array}$ \\
\hline 3. Permanent crops & 2.2 & (permanent crops) \\
\hline 4. Forest and semi- & 3.1 .1 & (broad-leaved forests) \\
natural areas & 3.2 .4 & (transitional woodland scrub) \\
\hline 5. Reafforestation areas & 3.1 .2 & (coniferous forests) \\
\hline $\begin{array}{l}\text { 6. Shrubby and/or } \\
\text { herbaceous }\end{array}$ & 3.2 .2 & $\begin{array}{l}\text { (moors and heathlands) } \\
\text { (natural grassland) }\end{array}$ \\
vegetation areas & 3.2 .1 & (open spaces with little or) \\
& 3.3 & no vegetation \\
\hline
\end{tabular}

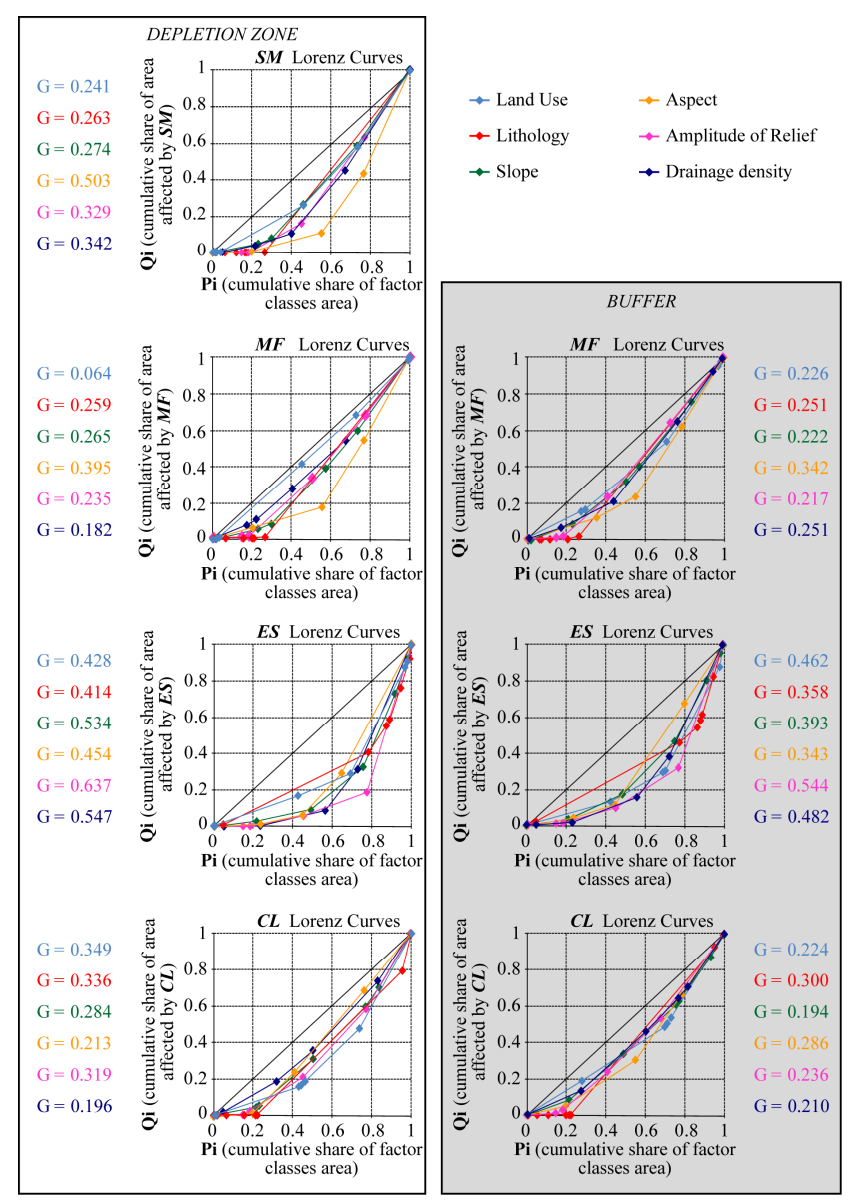

Fig. 7. Lorenz curves for each causal factor and each landslide type. Different curves are computed for depletion zones (or the whole area affected by shallow mass movements) and for the $50 \mathrm{~m}$ outer buffer areas. quantify the capability of the factors to discriminate the spatial distribution of the landslides. Examining the density of the depletion zones in the different $L$-classes, it can be stated that MF and SM preferentially develop on clay and sandy clay, while ES are homogeneously distributed over continental deposits, conglomerate, clay, sandy clay, and flysch deposits, but always on steep slopes. CL mostly developed on clay and sandy clay and on dolomitic limestone. Similar frequency of buffer areas and depletion zones was observed over the classes of this causal factor.

\subsection{Factor selection}

For the study case, we noted that a minimum of 2 and a maximum of 4 slope causal factors had to be selected for the susceptibility analysis. In fact, since the extent of the study area is of about $120 \mathrm{~km}^{2}$, we calculated that the intersection of more than 4 factors (each one reclassified in no less than 5 categories) resulted in vUCUs with an extent comparable to the factor map resolution and thus not statistically significant (Clerici et al., 2010).

Figure 7 shows the Lorenz curves for the considered landslides, while Fig. 8 shows the histograms of the obtained $G$ values for each landslide type, the matrix of the degree of association/correlation between the pairs of factors, and the tables indicating the factors finally selected for each landslide type. Only a few pairs of factors have relatively higher absolute values of correlation: in particular, $S$ and AR (Pearson correlation of 0.48 ), AR and $D$ (Pearson correlation of -0.36 ), and $D$ and $L$ ( $\eta^{2}$ index value of 0.29$)$.

The most influential factor for MF is $A$ ( $G$ value of 0.395 , Fig. 7) using depletion zones, because they are greatly clustered on the north and east-facing slopes, as shown in Fig. $6 \mathrm{~b}$. Land use was always discarded, since MF are widespread in arable lands, semi-natural areas, and shrubby and herbaceous vegetation lands, which are also the three most frequent classes of this factor. Moreover, by using the depletion zones, the $S$, AR, $A$, and $L$-factors were selected, while, when using the MF buffer areas, only factors $D$ and $A$ were finally selected, and the other factors related to the topography were discarded. This discrepancy was also observed for other landslide types. In order to discuss this apparent contradiction (same study area, same type of landslide, different influencing factors), we noted that the failure occurrence generally causes strong topographic modifications in correspondence of the depletion zones with respect to the general slope morphology. As a consequence, the topographic parameters become more distinctive for the depletion zones, and generally less effective in estimating the probability of a landslide type event when we consider buffer areas. Moreover, in the same example, $L$ was discarded and $D$ was selected, which makes sense, considering that the variability of $D$ reflects changes in lithological features. So the indirect influence of lithology was included even if $L$ was discarded. 

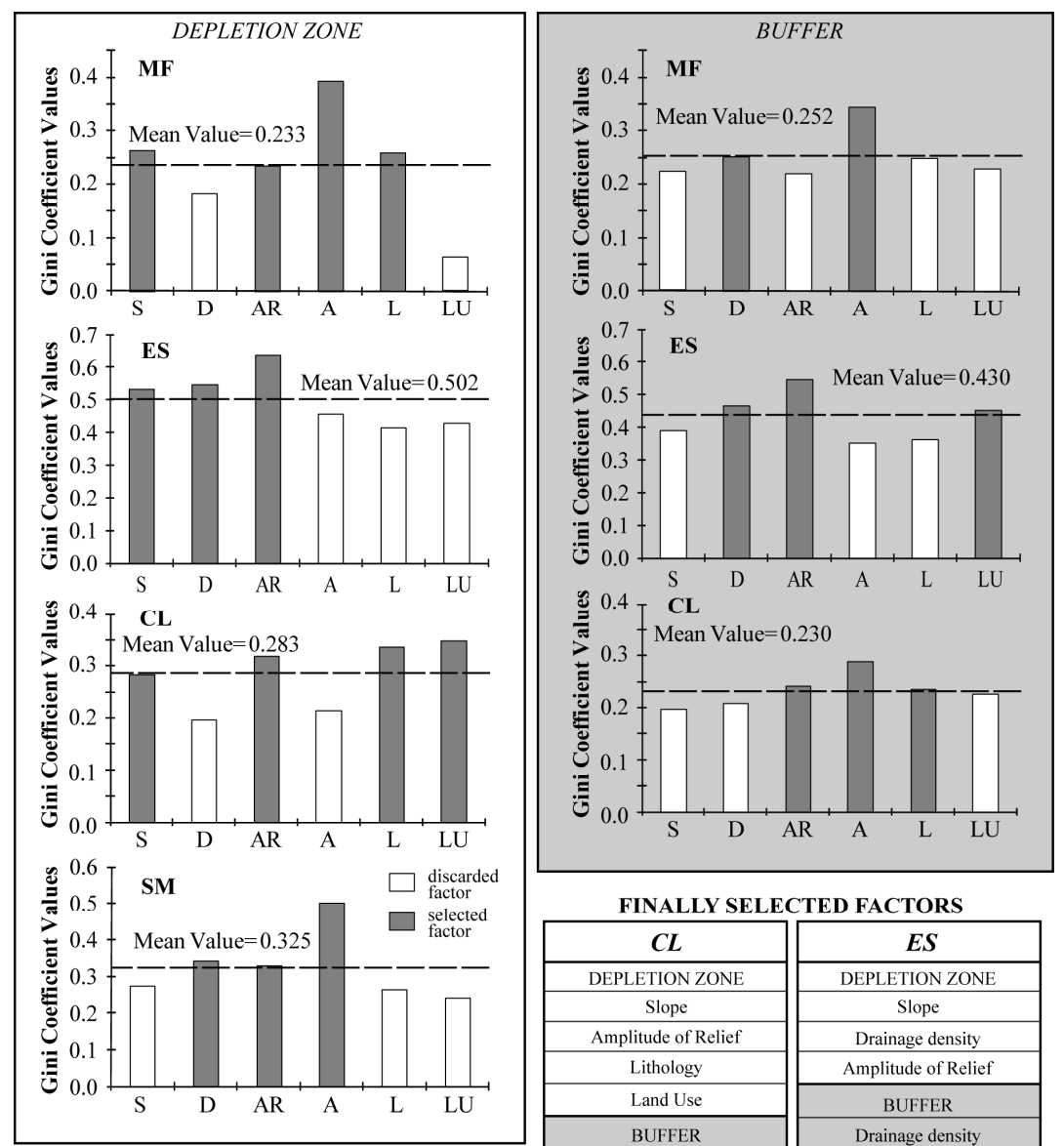

FINALLY SELECTED FACTORS

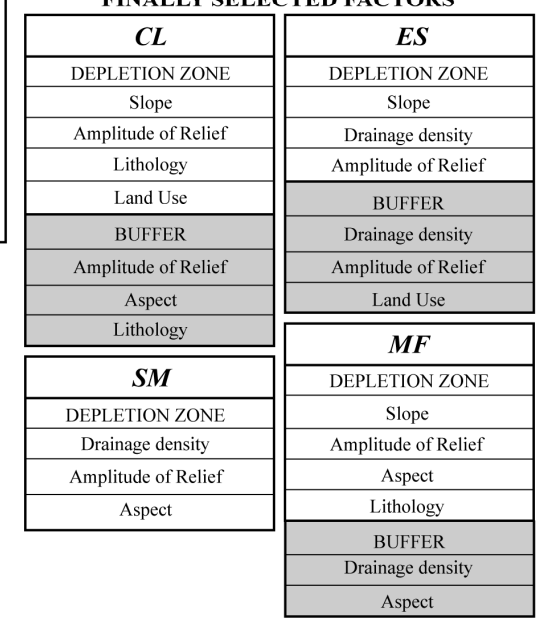

Fig. 8. Histograms of the Gini coefficient value distribution for each landslide type obtained after the spatial intersection between each causal factor map and each landslide type map. The matrix of association/correlation degree between pairs of factors and the tables indicating the factors finally selected for each landslide type are shown.

In the case of ES, the potential influencing factors generally show higher $G$-values ( 0.414 to 0.637 using depletion zones and 0.343 to 0.544 for the buffer areas). This suggests that in the study area, ES generally clustered in specific factor classes because, with respect to MF or SM, they are less closely linked to the clayey outcrops. Moreover, they are more concentrated where high values of AR occur. When considering ES buffer areas, the S-factor is discarded while LU becomes very important because the outer buffer areas from the depletion zones are clustered within forests (in most cases, on slopes reforested to mitigate the effects of denuda- tion). Together with $L$, also $A$ was always discarded for this landslide type. This suggests that ES in this area are poorly linked to this terrain parameter: in fact, landslide survey of the area confirm that ES are not strictly associated with north-facing slopes (wet soil conditions), as mud flows do. Instead, they generally occur on coherent litologies, or where weaker lithologies have sandy, gravel, conglomeratic, or volcanic caprocks at the hillslope summit which help in preserving high values of AR.

For CL susceptibility assessment, $S, \mathrm{AR}, L$, and LU were selected as causal factors when using depletion zones, while 
Table 2. Classification of Geological Units in Lithological classes.

\begin{tabular}{|c|c|}
\hline Lithological units & $\begin{array}{l}\text { Geological units } \\
\text { (from Carta Geologica d'Italia, at the scale 1:100000) }\end{array}$ \\
\hline \multirow{3}{*}{ Quaternary continental deposit } & Pebbly, sandy and clayey sandy alluvial deposits \\
\hline & Slope talus \\
\hline & Eluvium/colluvium - red shales - black shales \\
\hline Volcanic rock & Trachybasalt and olivinic andesite \\
\hline \multirow{2}{*}{ Conglomerate } & Polygenic puddingstone and sandstone \\
\hline & Polygenic puddingstone locally containing Cirripeds and Oysters \\
\hline \multirow{2}{*}{ Sand } & Sand and clayey sand \\
\hline & Sand and clayey sand with shells, pudding lenses and peat \\
\hline \multirow{2}{*}{ Clay and sandy clay } & Clay and sandy clay with pudding lenses and scattered pebbles \\
\hline & Interbeds of fossiliferous clay and sandy clay \\
\hline Limestones & Organogenic calcarenites \\
\hline \multirow{2}{*}{ Flysch } & Sandstone and siltstone \\
\hline & Clay, silty clay, marly clay with calcareous interbeds \\
\hline \multirow{4}{*}{ Dolomitic limestone } & Thin layered jasper variously colored and often weathered \\
\hline & White and gray layered limestone with chert nodules \\
\hline & $\begin{array}{l}\text { Limestone and dolomitic limestone - marls and calcareous marls intercalated } \\
\text { to clay layers }\end{array}$ \\
\hline & Nodular reddish limestone and marly limestone - dolomitic limestone \\
\hline
\end{tabular}

Table 3. Number and mean extent of the vUCUs of each susceptibility zonation described in the text.

\begin{tabular}{llcrr}
\hline $\begin{array}{l}\text { Landslide } \\
\text { type }\end{array}$ & $\begin{array}{l}\text { Slope instability } \\
\text { landform }\end{array}$ & $\begin{array}{l}\text { Combined factors } \\
\text { (defining vUCUs) }\end{array}$ & $\begin{array}{r}\text { Number of } \\
\text { vUCUs }\end{array}$ & $\begin{array}{r}\text { Mean extent of the } \\
\text { vUCUs }\left(\mathrm{m}^{2}\right)\end{array}$ \\
\hline \multirow{2}{*}{$\mathrm{CL}$} & $\begin{array}{l}\text { depletion zone } \\
\text { buffer }\end{array}$ & $\begin{array}{c}S, \mathrm{AR}, L, \mathrm{LU} \\
\mathrm{AR}, A, L\end{array}$ & 568 & $\begin{array}{r}207356.54 \\
26232227.19\end{array}$ \\
\hline \multirow{2}{*}{$\mathrm{MF}$} & depletion zone & $S, \mathrm{AR}, A, L$ & 567 & 207722.25 \\
& buffer & $D, A$ & 23 & 5120805.00 \\
\hline \multirow{2}{*}{$\mathrm{ES}$} & depletion zone & $S, D, \mathrm{AR}$ & 126 & 934750.12 \\
& buffer & $D, \mathrm{AR}, \mathrm{LU}$ & 112 & 1051593.89 \\
\hline SM & portion of hillslope & $D, \mathrm{AR}, A$ & 93 & 1266435.65 \\
& affected by SM & & & \\
\hline
\end{tabular}

$\mathrm{AR}, A$, and $L$ were selected when using buffer areas. The recurrent exclusion of $D$ for $C L$ is reasonable, if we consider that this landslide type usually occurs in variable conditions of permeability, lithology and rock fracturing.

The most influential factors for the SM distribution are $D$, $\mathrm{AR}$, and $A$, similarly to those obtained for MF, except for the $S$-factor, which does not strongly influence the presence of this type of slope instability in the study area. This is consistent with the abundance of small mud flows within the SM type.

In the Upper Orcia Valley case, we did not need to exclude a preselected factor using the correlation matrix because no more than 4 factors ever showed $G$-values above the mean (case b2 in Fig. 2b). 
To sum up, using depletion zones for the bivariate analysis generally resulted in higher $G$-values than using buffer areas. Moreover, the analysis performed using the buffer areas always led to the exclusion of the $S$-factor. These facts can depend on the widespread levelling practices for agricultural purposes, which have increased starting from the seventies (thus before the occurrence of the majority of the mapped landslides). These activities tend to rapidly smooth the natural roughness of the hillslope surface, thus causing the $\mathrm{S}$ factor to become less variable in space and not so discriminant as a causal factor. Conversely, landslides occurring on these surfaces generally cause $\mathrm{S}$ discontinuities in correspondence of the depletion zones. Moreover, $D$ parameter can increase just after a landslide event, and then progressively decrease with time. On the other hand, $L, A$, and AR-values should not significantly change after a landslide event (if not very large).

\subsection{Susceptibility assessment}

From the intersection of the selected factor maps and the different landslide type inventories, seven vUCU maps have been drawn up: four derived from the factors selected using depletion zones, and the other three from the factors selected using buffer areas, excluding the case of SM. The number and mean extent of the vUCUs are summarized in Table 3. The further overlay of each vUCU map with the corresponding landslide map led to the processing of seven susceptibility maps, two for each landslide type (one using depletion zones, the other using buffer areas, except for SM). These maps are based on the conditional probability of each vUCU to be affected by the occurrence of a landslide type event, as shown in Fig. 9.

For each landslide type, the susceptibility index $\left(S_{\text {index }}\right)$ corresponds to the conditional probability of future landslide event, given the selected number of factors. $S_{\text {index }}$ values were classified in a suitable number of categories and we decided to use the same color scale for the seven susceptibility maps in order to compare the obtained zonation maps and examine the relative distribution of susceptibility index values.

\subsubsection{Susceptibility maps}

The obtained susceptibility maps (Fig. 9) show the spatial probability of future landslide events for each landslide type in the study area. Most of the maps indirectly contain information on the discarded causal factors, since the performed factor selection was efficient in detecting the most discriminant factors. This is the case of the ES susceptibility map obtained using depletion zones that shows the maximum susceptibility in correspondence of outcrops of coherent lithologies on the eastern ridge of Castelluccio-Mt. Cetona ridge, even if factor $L$ was discarded. In fact, the higher $S_{\text {index }}$ values have been caused by a combination of $D, \mathrm{AR}$, and $S$-values clearly related to the outcrop of the most coherent lithologies. Moreover $D, \mathrm{AR}$, and $S$ contained an intrinsic set of additional information that allowed estimating high probability values: for example, $D$ is strictly linked not only to the permeability of rocks but also to the presence of vegetation cover and to the spatial distribution of the mean annual rainfall. As well as for ES, also the MF susceptibility map derived from buffer areas, even if having discarded the $L$ factor, fits well the lithological outcrop distribution: the highest $S_{\text {index }}$ values concentrate where clay or clayey sand crop out, and particularly the town of Contignano results quite seriously prone to this type of landslide, as well as to SM. Moreover, among the clayey slopes, the northeast-facing ones are the most susceptible to MF, since they are also dip slopes.

However, the range of $S_{\text {index }}$ values is very different for the landslides type maps, since the conditional probability values are sensitive to the number and to the extent of the map units: in fact, the density of past landslides decreases with the increase of the vUCU area. In the case study, the MF susceptibility maps (Fig. 9) are characterized by low $S_{\text {index }}$ values $(<10 \%)$, which can reflect the low lithological diversity of slopes in the study area with a clear prevalence of clay compared with the other lithologies, so that MF are likely to occur on most of the slopes. But it must be outlined that the MF area ratio within the vUCUs, and consequently the $S_{\text {index }}$ values, were underestimated since in the study area MF are frequent and rapidly levelled by the intense agricultural activity. Thus, many of them were not mapped or, especially the smallest ones (not mappable at the scale 1:10000), were placed in the SM database. Nonetheless, the maps well evidence the areas relatively most susceptible to future landslides.

The CL susceptibility map obtained using depletion zones shows not very high $S_{\text {index }}$ values for most of the area, apart from some small regions with both clayey and quite steep slopes, where the probability reaches the $33-45 \% S_{\text {index }}$ class, located close to the western divide and in the surroundings of Mt. Calcinaio. Multivariate analysis showed that on these slopes, not only reforestation failed to curb slope instability processes, but the re-planted trees represented an overload that favored landsliding. In fact, even if replanting trees has decreased the mud flows occurrence and runoff intensity, on the other hand they represented an overload on the hillslopes that sometimes favored deeper landslides, as ES and CL. In the case of this type of landslide, the map derived from buffer areas provides less information about the most susceptible areas because the $S_{\text {index }}$ values are in a very much narrower range (between 0 and $11 \%$ ).

The SM susceptibility map confirms that $A$ is the most influential factor for this type of landslide. In particular, SM occur mostly on the wetter north-facing slopes, then preferentially where AR and $D$ show medium to high values. The susceptibility map for this type of slope instability process clearly show the wider extent of the higer $S_{\text {index }}$ values, underlining that these shallow mass movements represent a serious threat for the stability of the arable and grazing lands in Upper Orcia Valley. 

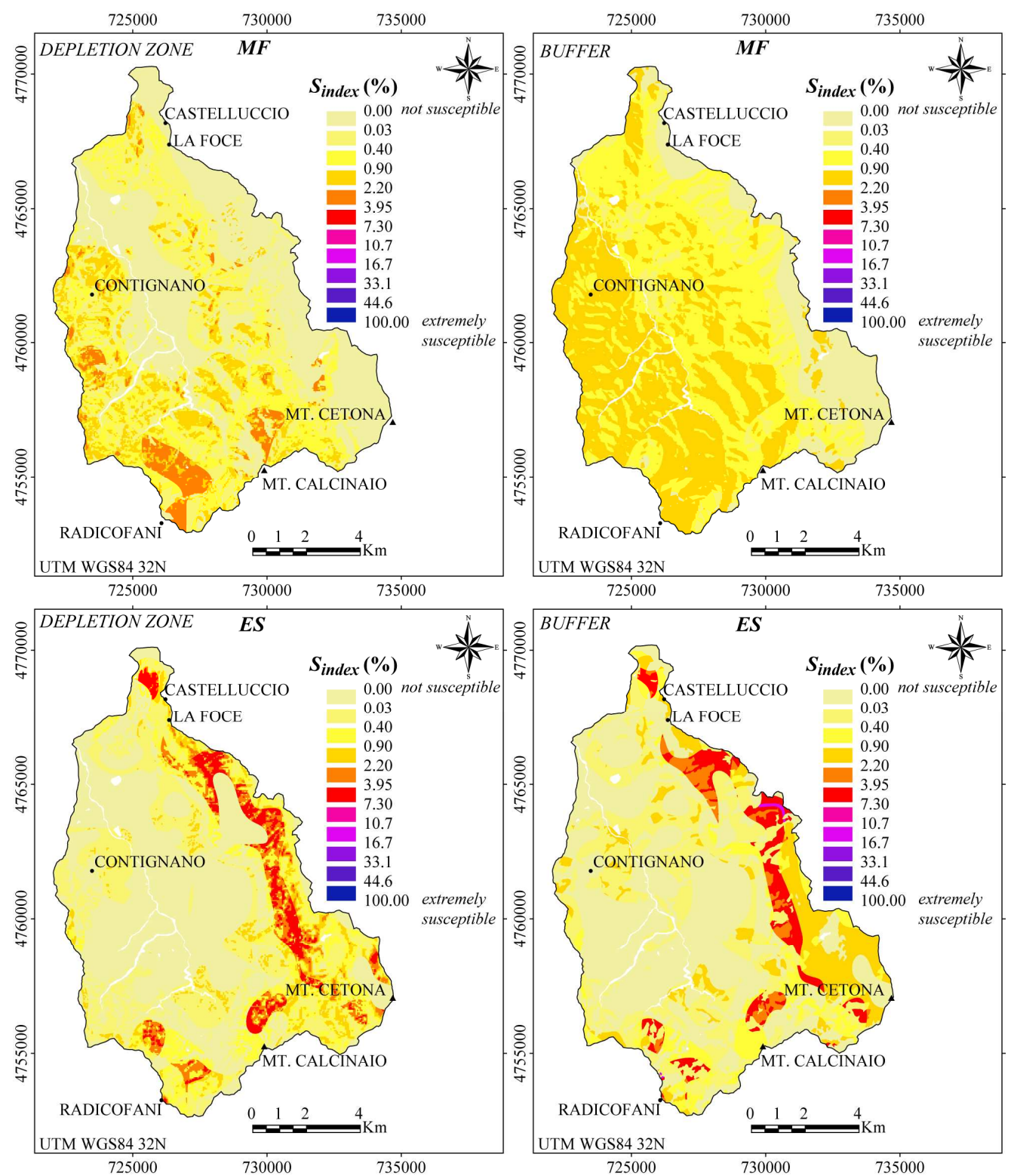

Fig. 9a. Susceptibility maps of the Upper Orcia Valley obtained through the conditional analysis for each landslide type. For each landslide type, the susceptibility index $\left(S_{\text {index }}\right)$ values correspond to the conditional probability of the landslide event, given the selected number of causal factors. $S_{\text {index }}$ values are classified in 11 intervals.

\subsection{Validation}

Since the landslide inventory was created using two different sets of aerial photos (years 1988-1989 and 1994), a temporal subdivision of the dataset was made, with the training subset containing landslides that occurred before 1988 and the test subset containing landslides that occurred after the same year, thus simulating an analysis performed in 1988. Validation was not performed for the SM because temporal information was not available (they were mapped after field survey). Neither was a spatial partition possible for SM, be- cause this type of landslide includes portions of hillslopes affected by small and frequent mud flows, the latter periodically leveled by farmers and difficult to be mapped. So while the extent of these areas is considerable, their number is not high enough for a spatial partition.

The validation outlined that success-rate curves obtained from the analysis of buffer areas generally show lower initial steepness compared with the curves generated using the depletion zones (Fig. 10). This can be explained considering the more specific terrain conditions of the depletion zones, due to the strong modification generally determined 

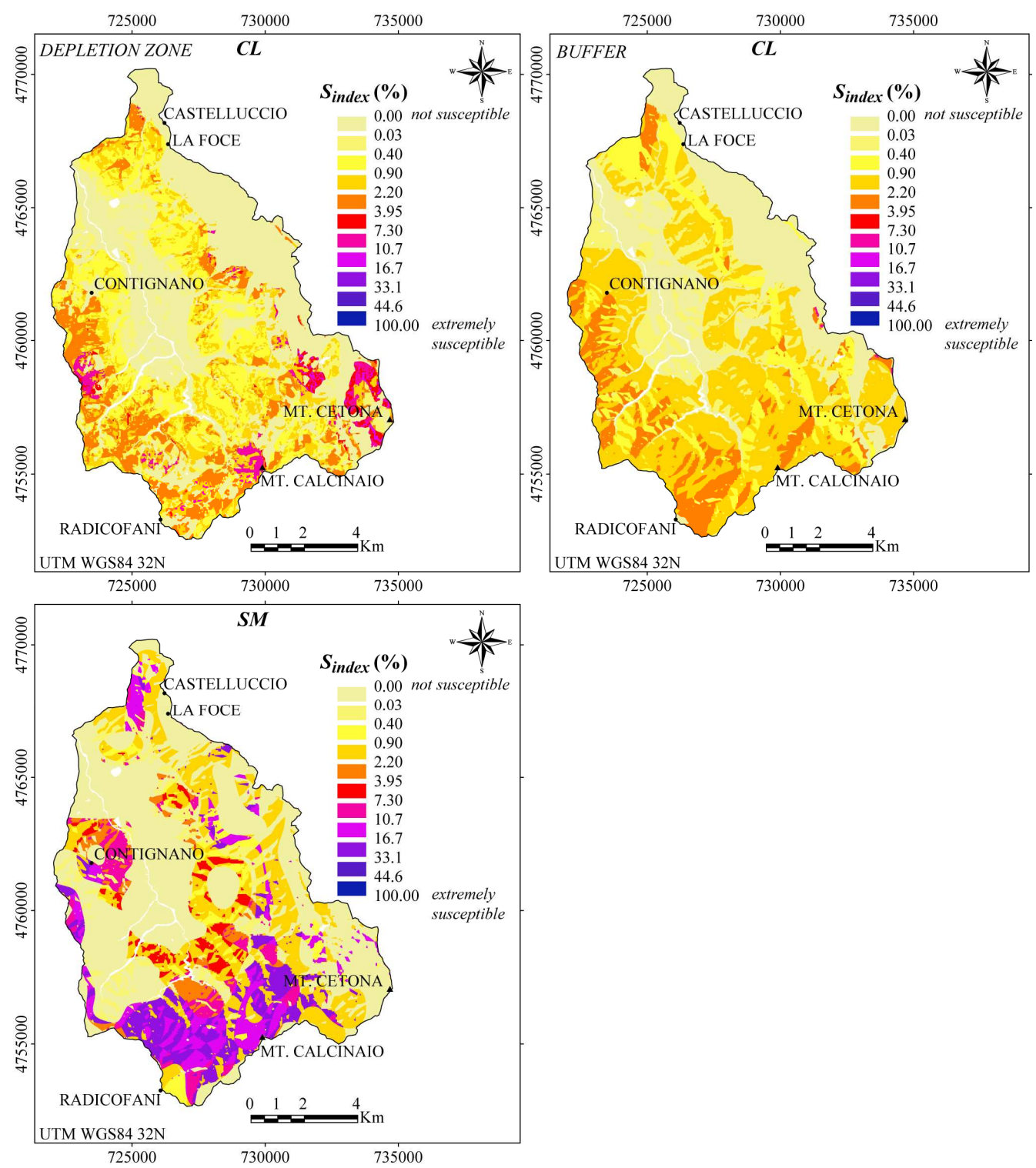

Fig. 9b. Susceptibility maps of the Upper Orcia Valley obtained through the conditional analysis for each landslide type. For each landslide type, the susceptibility index $\left(S_{\text {index }}\right)$ values correspond to the conditional probability of the landslide event, given the selected number of causal factors. $S_{\text {index }}$ values are classified in 11 intervals.

by landslide occurrence. Moreover, the buffer areas are not always more representative of the environmental conditions preceding the landslides. In fact, some gravitational movements often occur in areas where other landslides already took place and are thus characterized by post-event terrain conditions. This is, for example, the case of new crowns developed upwards from older landslide scarps.

The best success-rate curve for MF was the one generated using the depletion zones (Fig. 10a). Even if the corresponding prediction-rate curve is not monotonically decreasing, its first part is considerably steep, indicating that the most hazardous $6 \%$ of the predicted area estimates the distribution of
$29 \%$ of the MF that occurred within the following $20 \mathrm{yr}$ (after 1988). On the other hand, the prediction-rate curve generated using the buffer areas (Fig. 10b) indicates that the "future" landslides are well estimated within the classes 0-25\% and $60-100 \%$, so that the classes included in these intervals are effective prediction classes.

Both the success-rate curves for ES are very well shaped (their steepness smoothly decreases monotonically; Fig. 10c, d), while the corresponding prediction-rate curves are not so satisfying because the curve generated considering depletion zones shows a discontinuous trend and that generated using buffer areas is not very far from the 1:1 line, indicating a 


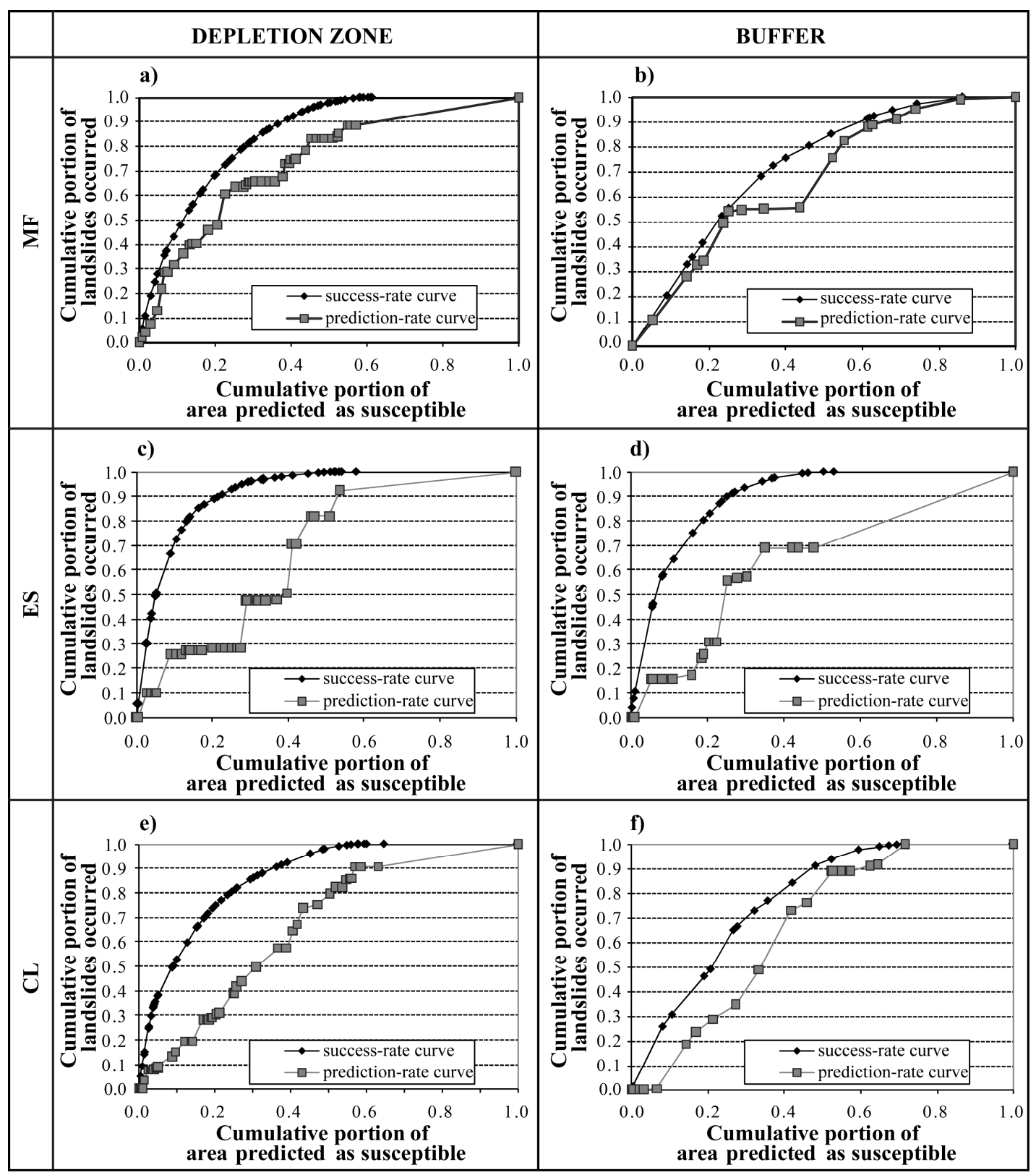

Fig. 10. Prediction- and success-rate curves for mud flows, earth slumps, and complex landslides generated using the procedure proposed by Chung and Fabbri (2003) adapted for vector datasets.

certain degree of randomness in the prediction results. This finding can be explained by considering that the test subset for this type of landslide is not very large, thus producing some randomness in the probability estimation of future events occurring in the areas predicted as hazardous using the training subset. In this case, the best model should be chosen only based on the best success-rate curve, which suggests selecting the map prepared using the depletion zones (steeper slope of the success-rate curve in the initial part).

The validation curves for the CL susceptibility evaluation show that the use of the depletion zone area is somewhat bet- ter than that of the buffer areas because the initial steepness of the prediction-rate curve is higher (Fig. 10e, f).

\section{Discussion}

Our contribution is focused on an unbiased causal factor selection procedure when performing conditional analysis in assessing landslide susceptibility. The obtained results confirm that the unbiased selection of controlling factors is a crucial phase for landslide susceptibility evaluation. However, 
in the performance of the landslide susceptibility method presented here, the following tricky problems occurred, some of which may be ascribed to our method, others affecting all statistical approaches.

First of all, both the heuristic and the statistical choice of causal factors require an a priori knowledge of the main causes of landsliding, as the potential factors must be not only spatially correlated with the distribution of landslides but also in cause/effect relationships with them. This can sometimes lead to the exclusion of variables spatially wellcorrelated with landslide distribution but representing a landslide effect more than a cause for landslides. For the same reason, factors that may vary in response to environmental changes or economical needs, such as land cover, should be used only if significant modification have not been observed during the time interval considered for the landslide inventory.

Once the potential factors have been correctly identified, a further constraint of a successful landslide susceptibility evaluation lies in their suitability for each study case: in fact, each causal factor can be more or less discriminant in explaining the distribution of the same landslide type events in different areas. Our procedure for factor selection provides a useful tool to filter the right set of causal factors really causing landslides in each study area. To give an example, some factors, such as lithology and slope, are the most frequently considered in the international literature on landslide susceptibility evaluation (Crozier, 1984; Guzzetti et al., 1999; Irigaray et al., 1999; Fernandez et al., 2003; Ayalew and Yamagishi, 2005). But in our study case, we demonstrated that they are not really effective in explaining the distribution of the occurred mud flows. In fact, clayey outcrop is the predominant lithology in the area $(75 \%)$. This implies that MF buffer area distribution is not well explained by the $L$ factor. On the other hand, $D$ was selected (Figs. 6d and 7), since it indirectly accounts as well for geological (lithology, fracturing, permeability, etc.) and morphological (slope, shape, and length of slopes, etc.) conditions characterizing the area (Strahler, 1957), thus it better explains the present MF distribution than $L$. At the same time, $S$ was discarded when considering MF buffer areas. This result does not mean that $S$ is not one of the most important factors generally triggering landslides, but that in the study case MF are uniformly distributed on different classes of $S$ (Fig. 7) as confirmed by field surveys.

To sum up, the applied susceptibility evaluation procedure is useful in filtering, among the potential factors, the ones really discriminant in inducing future landslides for a given study area, especially when this is poorly known. At the same time, it allows limiting the number of factors to be used in conditional analysis, thus avoiding generating too small and diverse map units. In fact, the smaller the map units are, the less the landslide probability will be statistically significant for the same landslide inventory. Moreover, the factor selection method, if combined with the study of correlation between independent variables, does not result in the loss of information, since the discarded factors are often indirectly accounted for by other variables, as demonstrated by the exclusion of $L$ in ES susceptibility analysis.

Some sources of uncertainty were detected in the model performance, but most of them are common to all the landslide susceptibility statistical models. First of all, the quality of the analysis strongly depends on the quality and resolution of the input data (landslide inventory and causal factor maps) and of their representation in GIS environment. Landslide identification and mapping is an error prone procedure, due to the scale-dependent minimum mappable unit, to the lack of historical data, and to the degree of agricultural exploitation of slopes. In the study case, for example, the quality of mud flow inventory affected the landslide susceptibility assessment: in fact the area affected by mud flows in the map units, and consequently the calculated susceptibility index, were surely underestimated since in the study area MF are frequently and rapidly levelled for the intense agricultural activity. In cases like this, a possible solution for improving the results could be the introduction of a wider set of potential causal factors when applying our selection procedure in order to search for factors with higher $G$-values. Moreover, future outcomes could entail the use of some statistical procedure to associate an error to prediction results.

Another tricky step for a successful susceptibility evaluation is the choice of the features to be used to represent the occurred landslides in the inventory. The performed validation suggested some interesting remarks about the advisability of using either depletion zones or outer buffer areas from depletion zones as representative of the landslides. More precisely, the results underlined that the choice is delicate since, on one hand, buffer zones are more representative of the conditions that preceded the landslide occurrence, but, on the other hand, some gravitational movements can reactivate some previously occurred ones. From this perspective, the obtained validation curves did not allow performing a unique choice for the study area. To this end, a possible development could involve the detection (and separate analysis) of the reactivated landslides.

\section{Conclusions}

The landslide susceptibility of the Upper Orcia Valley was evaluated through an unbiased factor selection procedure, followed by conditional analysis. The assessment was performed for the most frequent landslide types and considering separately the landslides depletion zones and the outer buffers from depletion zones. Different causal factors were proved to have influence on each landslide type. Conditional analysis allowed the zonation of conditional probability of future landslide occurrence $\left(S_{\text {index }}\right)$. A validation procedure was finally applied, in which a temporal subdivision of landslide inventory was performed. The results confirmed the 
efficiency of the selection procedure, which allowed using few causal factors without losing information on the indirect influence of the discarded ones. Even so, the applied susceptibility assessment methodology is affected by some sources of uncertainty, in particular those generally associated with all the statistical approaches, for which the quality of the result is strongly sensitive to the quality of the input data.

In conclusion, the conditional analysis, preceded by a bivariate statistical analysis for causal factor selection, provided satisfactory results for the unbiased prediction of landslide susceptibility for the Upper Orcia Valley. The method is conceptually simple but, at the same time, effective in evaluating the conditional probability of hazardous events given a certain combination of causal factors. Even if the knowledge of the study area is an important precondition for successful susceptibility analysis, the proposed factor selection procedure proved to be a useful tool for the unbiased detection of the factors really discriminant for landslides in the study area, and can be very helpful when analyzing new areas. This procedure allowed us to overcome one of the limits of the conditional analysis, which consists in the lack of statistical significance of too small vUCUs generated by the intersection of a large number of subjectively defined influencing factors. The factor selection procedure proposed here differs from others already suggested in the literature, which provide for selecting the most significant factors after having computed all of their possible combinations and having tested the results. Our factor selection method makes the susceptibility analysis less cumbersome and simplifies the entire procedure, since it provides for using simple statistical indices. Moreover, the use of vector datasets allow to create vector easy-to-read susceptibility maps in which the fragmentation generally characterizing raster outputs is avoided. These characteristics make this susceptibility method easy to understand and each resulting map easy to read, thus suitable for policy makers in planning land management strategies.

Acknowledgements. The authors thank the reviewer Dalia Kirschbaum and another anonymous referee, as well as the editor Paola Reichenbach for their significant comments and precious suggestions that greatly improved the manuscript. The authors are also grateful to Cecilia Vergari for her precious advices on statistics. The research was funded by the Ministry of Instruction, University and Research (MIUR), PRIN Project 2007 "Messa a punto di un modello integrato per la valutazione preventiva dell'erosione idrica del suolo in ambiente mediterraneo" (National coordinator G. Rodolfi, Research Unit coordinator E. Lupia Palmieri).

Edited by: P. Reichenbach

Reviewed by: D. Kirschbaum and another anonymous referee

\section{References}

Acocella, V. and Rossetti, F.: The role of extensional tectonics at different crustal levels on granite ascent and emplacement: an example from Tuscany (Italy), Tectonophysics, 354(1-2), 71-83, doi:10.1016/S0040-1951(02)00290-1, 2002.

Agterberg, F. P.: Geomathematics. Mathematical background and geo-science applications, Elsevier Scientific Pub. Co, Amsterdam, New York, 1974.

Aleotti, P., Balzelli, P., and De Marchi, D.: Le reti neurali nella valutazione della suscettibilità da frana, Geologia Tecnica Ambientale, 5(4), 37-47, 1996.

Atkinson, P. M. and Massari, R.: Generalized linear modeling of susceptibility to landsliding in the central Apennines, Italy, Comput. Geosci., 24, 373-385, 1998.

Ayalew, L. and Yamagishi, H.: The application of GIS-based logistic regression for landslide susceptibility mapping in the KakudaYahiko Mountains, Central Japan, Geomorphology, 65(1-2), 1531, doi:10.1016/j.geomorph.2004.06.010, 2005.

Baeza, C. and Corominas, J.: Assessment of shallow landslide susceptibility by means of multivariate statistical techniques, Earth Surf. Proc. Land., 26, 1251-1263, 2001.

Baldi, P., Bellani, S., Ceccarelli, A., Fiordalisi, A., Squarci, P., and Taffi, L.: Correlazioni tra le anomalie termiche ed altri elementi geofisici e strutturali della Toscana meridionale, Studi Geologici Camerti, 1, 139-149, 1994.

Bonham-Carter, G. F., Agterberg, F. P., and Wright, D. F.: Weights of evidence modelling: a new approach to mapping mineral potential, in: Statistical Applications in the Earth Sciences, edited by: Agterberg, F. P. and Bonham-Carter, G. F., Geological Survey of Canada, 171-183, 1989.

Bosi, C., Dramis, F, and Gentili, B.: Carte geomorfologiche di dettaglio ad indirizzo applicativo e carte di stabilità a base geomorfologica, Geologia Applicata ed Idrogeologia, 20(2), 53-62, 1985.

Brabb, E. E.,: Innovative approaches to landslide hazard mapping, in: Proceedings of the 4th International Symposium on Landslides, Toronto, 1984.

Buccolini, M., Gentili, B., Materazzi, M., and Piacentini, T.,: Late Quaternary geomorphological evolution and erosion rates in the clayey peri-Adriatic belt (central Italy), Geomorphology, 116(12), 145-161, 2010.

Carmignani, L., Decandia, F. A., Fantozzi, P. L., Lazzarotto, A., Liotta, D., and Meccheri, M.: Tertiary extensional tectonics in Tuscany (Northern Apennines, Italy), Tectonophysics, 238(1-4), 295-310, 313-315, doi:10.1016/0040-1951(94)90061-2, 1994.

Carrara, A.: A multivariate model for landslide hazard evaluation, Math. Geol., 15, 403-426, 1983.

Carrara, A., Cardinali, M., Detti, R., Guzzetti, F., Pasqui, V., and Reichenbach, P.: GIS techniques and statistical models in evaluating landslide hazard, Earth Surf. Proc. Land., 20(5), 427-445, 1991.

Carrara, A., Cardinali, M., and Guzzetti, F.: Uncertainty in assessing landslide hazard and risk, ITC Journal, 2, 172-183, 1992.

Carrara, A., Cardinali, M., Guzzetti, F., and Reichenbach, P.: GIS technology in mapping landslide hazard, in: Geographical Information Systems, in: Assessing Natural Hazards, edited by: Carrara, A. and Guzzetti, F., Kluwer Academic Publisher, Dordrecht, 135-176, 1995.

Carrara, A., Crosta, G., and Frattini, P.: Geomorphological and 
historical data in assessing landslide hazard, Earth Surf. Proc. Land, 28, 1125-1142, 2003.

Chung, C. J. F. and Fabbri, A. G.: Probabilistic prediction models for landslide hazard mapping, Photogramm. Eng. Rem. S., 65(12), 1389-1399, 1999.

Chung, C. J. F. and Fabbri, A. G.: Validation of Spatial Prediction Models for Landslide Hazard Mapping, Nat. Hazards, 30(3), 451-472, doi:10.1023/B:NHAZ.0000007172.62651.2b, 2003.

Chung, C. J. F. and Fabbri, A. G.: Predicting landslides for risk analysis - Spatial models tested by a cross-validation procedure, Geomorphology, 94, 438-452, doi:10.1016/j.geomorph.2006.12.036, 2008.

Chung, C. F., Fabbri, A. G., and van Westen, C. J.: Multivariate Regression Analysis for Landslide Hazard Zonation, in: Geographical Information Systems in Assessing Natural Hazards, edited by: Carrara, A. and Guzzetti, F., Kluwer Academic Publisher, Dordrecht, 107-134, 1995.

Chung, C. J. F., Kojima, H, and Fabbri, A. G.: Stability analysis of prediction models for landslide hazard mapping, in: Applied Geomorphology: Theory and Practice, edited by: Allison, R., John Wiley \& Sons, Chichester, 3-19, 2002.

Ciccacci, S., Galiano, M., Roma, M. A., and Salvatore, M. C.: Morphological analysis and erosion rate evaluation in badlands of Radicofani area (Southern Tuscany-Italy), CATENA, 74(2), 8797, doi:10.1016/j.catena.2008.03.012, 2008

Clerici, A., Perego, S., Tellini, C., and Vescovi, P.: A GISbased automated procedure for landslide susceptibility mapping by the Conditional Analysis method: the Baganza valley case study (Italian Northern Apennines), Environ. Geol., 50, 941961, 2006.

Clerici, A., Perego, S., Tellini, C., and Vescovi, P.: Landslide failure and runout susceptibility in the upper T. Ceno valley (Northern Apennines, Italy), Nat. Hazards, 52(1), 1-29, doi:10.1007/s11069-009-9349-4, 2010.

Conoscenti, C., Di Maggio, C., and Rotigliano, E.,: GIS analysis to assess landslide susceptibility in a fluvial basin of NW Sicily (Italy), Geomorphology, 94(3-4), 325-339, doi:10.1016/j.geomorph.2006.10.039, 2008.

Cramer, H.: Mathematical methods of statistics, Princeton University Press, Princeton, N. J., 575 pp., 1999.

Crozier, M. J.: Field assessment of slope instability, in: Slope Instability, edited by: Brunsden, D. and Prior, D. B., Chichester, Wiley, 103-142, 1984.

Cruden, D. M. and Varnes, D. J.: Landslide types and processes, Special Report - National Research Council, Trans. Res. B., 247, 36-75, 1996.

Dai, F. C. and Lee, C. F.: A spatiotemporal probabilistic modeling of storm-induced shallow landsliding using aerial photographs and logistic regression, Earth Surf. Proc. Land., 28, 527-545, 2003.

Del Monte, M., Fredi, P., Lupia Palmieri, E., and Marini, R.,.: Contribution of quantitative geomorphic analysis to the evaluation of geomorphological hazards, in: Applied Geomorphology: Theory and Practice, edited by: Allison, R., John Wiley \& Sons, Chichester, 335-358, 2002.

Della Seta, M., Del Monte, M., Fredi, P., and Lupia Palmieri, E.,: Quantitative morphotectonic analysis as a tool for detecting deformation patterns in soft rock terrains: a case study from the southern Marches, Italy, Géomorphologie, 4, 267-284, 2004.
Della Seta, M., Del Monte, M., and Pascoli, A.: Quantitative geomorphic analysis to evaluate flood hazards, Geogr. Fis. Din. Quat., 28(1), 117-124, 2005.

Della Seta, M., Del Monte, M., Fredi, P., and Lupia Palmieri, E.: Space-time variability of denudation rates at the catchment and hillslope scales on the Tyrrhenian side of Central Italy, Geomorphology, 107(3-4), 161-177, doi:10.1016/j.geomorph.2008.12.004, 2009.

EEA: CLC2006 technical guidelines, EEA Technical report No. 17/2007, 2007.

Falaschi, F., Giacomelli, F., Federici, P. R., Puccinelli, A., D’Amato Avanzi, G., Pochini, A., and Ribolini, A.: Logistic regression versus artificial neural networks: landslide susceptibility evaluation in a sample area of the Serchio River valley, Italy, Nat Hazards, 50,551-569, doi:10.1007/s11069-009-9356-5, 2009.

Fernandez, T., Irigaray, C., El Hamdouni, R., and Chacón, J.: Methodology for landslide susceptibility mapping by means of a GIS application to the Contraviesa Area (Granada, Spain), Nat. Hazards, 30(3), 297-308, doi:10.1023/B:NHAZ.0000007092.51910.3f, 2003.

Gini, C.: Sulla misura della concentrazione e della variabilità dei caratteri, Atti del Regio Istituto Veneto di Scienze, Lettere e Arti, LXXIII(parte II), 1203-1248, 1914.

Gorsevski, P. V., Gessler, P., and Foltz, R. B.: Spatial prediction of landslide hazard using logistic regression and GIS, in: Proceedings of the 4th Int. Conference on Integrating GIS and Environmental Modeling, Alberta, Canada, 2000.

Guzzetti, F., Carrara, A., Cardinali, M., and Reichenbach, P.: Landslide hazard elavuation: a review of current techniques and their application in a multi-scale study, Central Italy, Geomorphology, 31, 181-216, doi:10.1016/S0169-555X(99)00078-1, 1999.

Guzzetti, F., Reichenbach, P., Ardizzone, F., Cardinali, M., and Galli, M.: Estimating the quality of landslide susceptibility models, Geomorphology, 81, 166-184, doi:10.1016/j.geomorph.2006.04.007, 2006.

Hammond, C., Hall, D., Miller, S., and Swetik, P.: Level I Stability Analysis (LISA) Documentation for Version 2, General Technical Report INT-285, USDA Forest Service Intermountain Research Station, 121, 1992.

He, Y. and Beighley, E. R.: GIS-based regional landslide susceptibility mapping: a case study in southern California, Earth Surf Proc. Land., 33, 380-393, 2008

Hollingsworth, R. and Kovacs, G. S.: Soil slumps and debris flows: prediction and protection, Bulletin American Association of Engineering Geologists, 18(1), 17-28, 1981

Irigaray Fernàndez, C., Fernández Del Castillo, T., El Hamdouni, R., and Chacón Montero, J.: Verification of landslide susceptibility mapping: a case study, Earth Surf. Proc. Land., 24, 537-544, 1999.

Iverson, R. M.: Landslide triggering by rain infiltration, Water Resour. Res., 36(7), 1897-1910, 2000.

Jenks, G. F. and Caspall, F. C.: Error on Choroplethic Maps: Definition, Measurement, Reduction, Ann. Assoc. Am. Geogr., 61(2), 217-244, 1971.

Lee, S., Ryu, J., Min, K., and Won, J.: Development of Two Artificial Neural Network Methods for Landslide Susceptibility Analysis, Proceedings of the Geoscience and Remote Sensing Symposium, IGARSS '01, IEEE 2001 International, 9-13 July 2001, 5, 2364-2366, doi:10.1109/IGARSS.2001.978003, 2001. 
Liotta, D.: Analisi del settore centromeridionale del bacino pliocenico di Radicofani (Toscana meridionale), B. Soc. Geol. Ital., 115, 115-143, 1996.

Lorenz, M. O.: Methods of Measuring the Concentration of Wealth, Publ. Am. Stat. Assoc., 9(70), 209-219, 1905.

Marini, R.: Contributo della geomorfologia quantitativa alla valutazione della pericolosità geomorfologica, $\mathrm{PhD}$ thesis, Università degli Studi di Roma "La Sapienza", Rome, 175 pp., 1995.

Montgomery, D. R. and Dietrich, W. E.: A physically based model for the topographic control of shallow landsliding, Water Resour. Res., 30(4), 1153-1171, 1994.

Montgomery, D. R., Wright, R. H., and Booth T.: Debris flow hazard mitigation for colluvium-filled swales, Bulletin Association of Engineering Geologists, 28(3), 303-323, 1991.

Neeley, M. K. and Rice, R. M.: Estimating risk of debris slides after timber harvest in northwestern California, Bulletin American Association of Engineering Geologists, 27(3), 281-289, 1990.

Nefeslioglu, H. A., Duman, T. Y., and Durmaz, S.: Landslide susceptibility mapping for a part of tectonic Kelkit Valley (Eastern Black Sea region of Turkey), Geomorphology, 94, 401-418, doi:10.1016/j.geomorph.2006.10.036, 2008.

Ohlmacher, C. G. and Davis, C. J.: Using multiple regression and GIS technology to predict landslide hazard in northeast Kansas, USA, Eng. Geol., 69, 331-343, 2003.

Okimura, T. and Kawatani, T.: Mapping of the potential surfacefailure sites on granite slopes, in: International Geomorphology 1986, edited by: Gardiner, V., J. Wiley \& Sons, Part I, 121-138, 1987.

Pack, R. T., Tarboton, D. G., and Goodwin, C. N.: GIS-based landslide susceptibility mapping with SINMAP, in: Proceedings of the 34th Symposium on Engineering Geology and Geotechnical Engineering, edited by: Bay, J. A., Logan, Utah, 1999.

Pearson, K.: Mathematical contributions to the Theory of the Evolution-III, Regression, Heredity and Panmixia, Philos. T. Roy. Soc. A, 187, 253-318, 1896.

Pradhan, B. and Lee, S.: Landslide susceptibility assessment and factor effect analysis: backpropagation artificial neural networks and their comparison with frequency ratio and bivariate logistic regression modeling, Environ. Modell. Softw., 25, 747-759, 2010 .
Remondo, J., Gonzales, A., Diaz de Teràn, J. R., Cendrero, A., Fabbri, A., and Chung, C. J. F.: Validation of Landslide Susceptibility Maps; Examples and Applications from a Case Study in Northern Spain, Nat Hazards, 30(3), 437-449, doi:10.1023/B:NHAZ.0000007201.80743.fc, 2003.

Soeters, R. and Van Westen, C. J.: Slope stability: recognition, analysis and zonation, in: Landslides: investigation and mitigation, edited by: Turner, A. K. and Shuster, R. L., Trasportation research board- National research council, 129-177, 1996.

Strahler, A. N.: Quantitative analysis of watershed geomorphology, Trans. Am. Geophys. Un., 38, 913-920, 1957.

Süzen, M. L. and Doyuran, V.: Data driven bivariate landslide susceptibility assessment using geographical information systems: a method and application to Asarsuyu catchment, Turkey, Eng. Geol., 71(3-4), 303-321, doi:10.1016/S0013-7952(03)00143-1, 2004.

Terlien, M. T. J., van Westen, C. J., and van Asch., Th. W. J.: Deterministic modelling in GIS-based landslide hazard assessment, in: Geographical Information Systems in Assessing Natural Hazards, edited by: Carrara, A. and Guzzetti, F., Kluwer Academic Publisher, Dordrecht, 57-77, 1995.

van Westen, C. J., Seijmonsbergen, A. C., and Manotvani, F.: Comparing Landslide Hazard Maps, Nat. Hazards, 20, 137-158, 1999

Varnes, D. J.: Landslide hazard zonation: a review of principles and practice, Commission of Landslide of IAEG, UNESCO, Natural Hazads, 3, UNESCO, Paris, 63 pp., 1984.

Wang, H. B. and Sassa, K.: Rainfall-induced landslide hazard assessment using artificial neural networks, Earth Surf. Proc. Land., 31, 235-247, doi:10.1002/esp.1236, 2006.

Zêzere, J. L., Trigo, R. M., and Trigo, I. F.: Shallow and deep landslides induced by rainfall in the Lisbon region (Portugal): assessment of relationships with the North Atlantic Oscillation, Nat. Hazards Earth Syst. Sci., 5, 331-344, doi:10.5194/nhess-5-3312005, 2005. 